\title{
Misplaced Inventory and Lead-Time in the Supply Chain: Analysis of Decision-Making on RFID Investment with Service Level
}

\author{
Li-Hao Zhang, ${ }^{1,2}$ Ti-Jun Fan, ${ }^{1}$ Wen-Chyuan Chiang, ${ }^{3}$ and Feng Tao ${ }^{1}$ \\ ${ }^{1}$ School of Business, East China University of Science and Technology, Shanghai 200237, China \\ ${ }^{2}$ Krannert School of Management, Purdue University, West Lafayette, IN 47907, USA \\ ${ }^{3}$ College of Business, University of Tulsa, Tulsa, 74104, USA \\ Correspondence should be addressed to Li-Hao Zhang; leehowzhang@hotmail.com
}

Received 13 February 2014; Accepted 25 June 2014; Published 23 July 2014

Academic Editor: Zhi-Hong Guan

Copyright (C) 2014 Li-Hao Zhang et al. This is an open access article distributed under the Creative Commons Attribution License, which permits unrestricted use, distribution, and reproduction in any medium, provided the original work is properly cited.

Radio-frequency identification (RFID), as the key technology of Internet of Things (IoT), has been hailed as a major innovation to solve misplaced inventory and reduce lead-time. Many retailers have been pushing their suppliers to invest this technology. However, its associated costs seem to prohibit its widespread application. This paper analyzes the situation of service level in a retail supply chain, which has resulted from misplaced inventory and lead-time. By newsvendor model, we analyze the difference between with- and without-RFID technologies in service level of centralized and decentralized supply chains, respectively. Then with different service levels, we determine the tag cost thresholds at which RFID technology investment becomes profitable in centralized and decentralized supply chains, respectively. Furthermore, we apply a linear transfer payment coefficient strategy to coordinate with the decentralized supply chain. It is found that whether the adoption of RFID technology improves the service level depends on the cost of RFID tag in the centralized system, but it improves the service level in the decentralized system when only the supplier bears the cost of RFID tag. Moreover, the same cost thresholds of RFID tag with different service levels exist in both the centralized and the decentralized cases.

\section{Introduction}

1.1. Motivation. Nowadays, customer service level is one of the most important key performance indicators in the supply chain. If it increases from $90 \%$ to $96 \%$, customers will surely be much more satisfied and buy more from the supply chain in the USA. Obviously, customer service level will greatly affect the profit of supply chain. To achieve higher customer service level, almost all the supply chains have placed a strong emphasis on the control of misplaced inventory and leadtime.

Misplaced inventory, one of the inventory inaccuracy styles in operations, is widely discussed in the retailer supply chain [1-6]. According to the surveys in DeHoratius and Raman [7], inventory records are inaccurate for $65 \%$ of the nearly 370,000 inventory records observed across 37 retail stores; $20 \%$ of the inventory records differ from the physical stock by six or more items, and approximately $12 \%$ of those items have no inventory on the shelf but the recorded inventory quantity is positive. At the same time, lead-time reduction can improve forecasting accuracy and the speed of response to market changes, get higher supply chain service levels, and reduce excess inventory and stockouts [8]. It has become one of the most important sources of competitive advantage. Granite Bay (http://www.granite-bay.com/reducing-lead-time.html (Last accessed October 2008)), a US-based consulting firm, has reported that, as a result of reducing many world-class manufacturers' lead-times by $50-80 \%$, they have increased their market shares and improved their profitability. Granite Bay regards lead-time reduction as the most important factor in achieving world-class operations.

"Internet of Things (IoT)" is a landmark emerging strategic industries in the 21st century, and it was first coined 
by MIT in the late 1990s. It refers to a "devices or sensors connected world" where objects are connected, monitored, and optimized through either wired, wireless, or hybrid systems. The Cisco Internet Business Solutions Group has reported that, in the next 10 years, the IoT is all about the potential economic value which will reach $\$ 14.4$ trillion all over the world, while the share of the Chinese market will reach $\$ 1.8$ trillion, accounted for $12 \%$ of the total in the world (http://www.newsking.us/news-4263717Cisco-stressed-the-potential-value-of-the-interconnectionof-all-things.html (April 8, 2013)). In 2012, IoT of the Chinese industries has been reached $¥ 365$ billion, and it is expected to reach more than $¥ 500$ billion in 2015 (http://en.wikipedia.org/wiki/Internet_of_Things January 2014). Radio frequency identification (RFID) technology is the key technical points of IoT, and it is a way to solve misplaced inventory and reduce lead-time. RFID is a contactless and low-power wireless communication technology which has applications in many areas of a supply chain, and it has been hailed as a major innovation to enhance the efficiency of a supply chain [9]. The basic premise of RFID is that a radio frequency $(\mathrm{RF})$ reader can provide real-time communication with numerous objects at the same time, reading as many as 200 tags in a second without requiring contact or a direct line of sight [10]. These advanced identification and communication characteristics of RFID can provide real-time information update and improve products' traceability and visibility among supply chains as well as increasing the automation operational process, reducing the time of manual operations, and increasing efficiency of manufacture, transportation, storage, and other links, so it can eliminate the misplaced inventory and reduce lead-time in the supply chains.

However, RFID technology is not yet cheap enough to become as common as barcoding technology. In recent years, several major retail chains have strongly promoted-or even mandated-the adoption of RFID by their suppliers, mostly at the pallet level. While RFID technology is suggested to enable substantial efficiency gains at the different stages of a supply chain, the associated costs are by no means negligible. For the retail supply chain, due to the huge number of commodities involved, the price of the RFID tag is the most important factor. For example, Asif and Mandviwalla [11] estimated that a typical consumer packaged goods supplier would spend between \$13 million and \$23 million for shipping 50 million cases per year, just for the cost of RFID tags. As a result, the substantial cost of RFID seems to prohibit its widespread use at the item level. Therefore, we must consider the cost threshold for adoption of RFID tags in the supply chain and the change of the supply chain profit and service level with/without RFID technology. In the recent years, several major retail chains have strongly promoted-or even mandated-RFID adopting by their suppliers. Generally, the upstream enterprise adopts RFID technology and bears its cost, but the downstream enterprise gains the profit. It has been pointed out by the practitioners that a compensation for the upstream enterprise is necessary to ensure the supply chain operations with RFID technology.
1.2. Research Questions and Main Results. In order to address the above issues, while the supply chain establishes a new business model under IoT environment, an RFID tag has been labeled on each product. We focus on the improvements that result from increasing the accuracy of inventory information and speeding up the processes. In order to ensure the increase of the supply chain's profit and performance, it is important to balance the increase of service level with the costs of RFID tag. This paper addresses the following research questions.

(1) How do the misplaced inventory and lead-time affect service level in a retail supply chain? RFID technology can eliminate the misplaced inventory and reduce the lead-time, but it also increases the cost of supply chain. Thus, what is the difference between with and without RFID technology in service level of centralized and decentralized supply chains, respectively?

(2) What is the decision-making on RFID technology investment with different service levels of centralized and decentralized supply chains, respectively?

(3) How does RFID technology affect the players' profit in decentralized supply chain? How can we coordinate it?

In spite of the significance of IoT in retail supply chains, the extant literature does not examine the above issues. The primary motivation of this research is to address this gap. We use theoretical and numerical example approaches to answer the research questions. We study two different settings: (1) a centralized supply chain where the supplier owns the retailer and (2) a decentralized and uncoordinated supply chain.

Firstly, we define the service level according to Iyer and Bergen [12], and it results from the misplaced inventory and lead-time of a two-stage supply chain with a supplier and a retailer. We assume that the market demand forecast error varies with lead-time reduction; Chen and Chuang [13] also assumed this in their simulation study. We, respectively, analyze the relationship not only between service level and misplaced inventory, but also between service level and leadtime. And we find that the service level increases with the decrease of the misplaced inventory rate, but with the increase of the lead-time reduction in both centralized and decentralized supply chains. When the supply chain adopts RFID technology, the service level increases with the decrease of the unit cost of RFID tag in centralized supply chain, but the unit cost of RFID tag does not affect the service level in decentralized supply chain.

Then, we theoretically analyze the cost threshold of RFID tag that becomes profitable in different service levels of centralized and decentralized supply chains. We find that the trends of service level and profit are different with different RFID tag prices, but the same cost-of-tag thresholds for RFID technology with different service levels exist in both the centralized and the decentralized cases.

Finally, when the variable tagging cost of RFID technology under a threshold improves the profit of both the decentralized supply chain and the retailer, the manufacturer's profit will be reduced. In this context, we prove that 
the linear transfer payment coefficient strategy can be used by the retailer to achieve Pareto improvement of the supply chain actors' profits. We also provide a numerical example to validate our theoretical findings.

The remainder of the paper is organized as follows. We discuss related literature and our contributions in Section 2 and present the base model with the assumptions and notations in Section 3. We discuss the decision-making on RFID technology investment with the perspective of service level in the centralized/decentralized supply chain in Sections 4 and 5. We provide numerical examples in Section 6, and in Section 7 we conclude our paper and point out the direction for further research. The proofs of key results are relegated to an appendix.

\section{Literature Review}

Although the specific research questions of this paper have not been addressed before, there are certain streams of existing literature that are relevant to our research. Our work is related to two streams of studies: the first stream deals with the service level of the supply chain and the second with the adoption of RFID technology by the supply chain in IoT environment.

The first stream of related literature consists of papers dealing with the service level of the supply chain. Thiel et al. [14] showed that the service-level quality is a nonmonotone function of the inaccuracy rate; that is, the service-level quality increases up to an inventory record inaccuracy level and subsequently decreases, and they also found that the same phenomenon between the function involving a level of safety stock defined by simulation and the function between the service-level quality and inventory record inaccuracy. Jha and Shanker [15] studied an integrated production-inventory model and the buyer level demand is assumed to be independent and normally distributed. They supposed a service level constraint corresponding to each buyer is included in their model, which limits that the stock-out level per cycle for each buyer is bounded. Specifying a service level avoids the difficult practical issue of explicitly estimating the shortage cost. Chen and Chuang [13] found that the shortening of lead-time affects not only the retailer's forecast accuracy, but also the service level of the supply chain. Glasserman and Wang [16], as well as Song and Yao [17], reached similar conclusions: the reduction of lead-time can speed up the response and improve the service level to the customers, raising the competitiveness of enterprises. Sieke et al. [8] used the service level references to the fraction of a manufacturer's demand filled by the supplier and analyzed two types of service level-based supply contracts that are designed by a manufacturer and offered to a supplier. They showed how the supplier responds to the service level contracts and how the contract parameters can be chosen, such that the supply chain is coordinated.

All of these studies supposed the service level as a constraint in the supply chain, designed a contract based on the service level that coordinates the supply chain, or found that the lead-time reduction will affect service level in a qualitative point of view. In contrast, we study the relationship not only between the service level and the misplaced inventory rate, but also between the service level and the lead-time reduction in a quantitative point of view, and we futurely explore the changes of the service level impact on the revenue of the centralized supply chain, decentralized supply chain, and its players.

More directly related to the present work is the literature on RFID technology adoption in the IoT environment. IoT semantically means "a worldwide network of interconnected objects uniquely addressable, based on standard communication protocols." For the management of supply chain under IoT, the related literature about adoption of RFID technology considered either the inventory inaccuracy elimination or lead-time reduction separately.

In the Table 1, we can easily find the difference between this paper and the most of existing literature. The research concentrates on adoption of RFID technology to solve the supply chain's inventory inaccuracy problem as follows. Gaukler et al. [18] assumed that the retailer acted as if it were not aware of the inventory inaccuracy problem. This approach greatly simplifies the mathematical analysis, reducing it to the level of a newsvendor problem. In their model, the retailer is conscious of the uncertainty with respect to inventory and adjusts its orders accordingly, such that its execution problems also affect the manufacturer. Rekik et al. $[3,4,19]$ performed several analyses in order to quantify the impact of inventory inaccuracy on inventory management. They defined separately the factors for inventory inaccuracy such as misplaced items, damage and spoilage, and supply errors. They dealt with each factor separately and analyzed the effect of RFID technology on supply chain inventory through a newsvendor model. They considered RFID to be a perfect technology that can eliminate all errors. Camdereli and Swaminathan [20] considered the case where a fixed and known proportion of the retailer's order quantity becomes unavailable for sale due to misplacement at the retailer. All misplaced products were recovered and salvaged at the end of the period. They analyzed the impact of such proportional loss on the retailer's optimal order quantity. They compared the performance of a decentralized supply chain with that of a vertically integrated supply chain and investigated how coordination can be achieved by means of buy-back and revenue-sharing contracts. Rekik and Sahin [6] modeled a set of scenarios depending on the technology available to track shrinkage in the store with/without RFID. They assumed that an inspection process is performed at a regular frequency of $N$ selling periods. The deployment of the RFID technology produces two benefits: total visibility of the shrinkage rate and the elimination of shrinkage errors. A comparison of the scenarios enables us to evaluate the economic impact of inventory record inaccuracies, which can be significant, particularly in systems with a poor estimation of the error parameter as well as with a high inspection cost.

Only a few studies have been undertaken theoretically on reducing lead-time by adoption of RFID technology. For example, Sari [21] constructed a four-echelon supply chain simulation model to verify the impact of RFID technology on supply chain performance. He concluded that integrating 


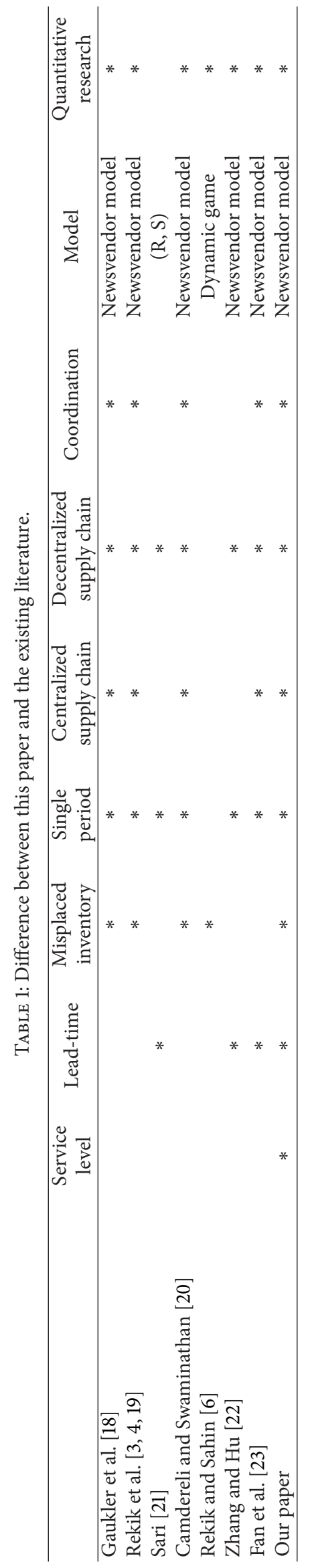


RFID within the supply chain provides greater benefits based on the intensive collaboration between the partners. He found RFID adoption to be the most beneficial in environments with longer lead-times and limited demand uncertainty. The supply chain could use RFID systems to reduce lead-times, thus increasing products' total useful shelf life. Zhang and $\mathrm{Hu}$ [22] studied the effect of leadtime compression on profit of supply chain players on the assumption that the market demand forecast error varies with lead-time based on VMI. Using a newsvendor model, they discussed the constraint condition of RFID technology cost that can improve the profit of supply chain. Fan et al. [23] supposed the RFID can reduce the lead-time of the supply chain and showed the revenue sharing contract can coordinate the supply chain with RFID technology, and they found that the interval of contract parameters would shrink, the retailer's optimal order quantity would reduce, and the supplier's wholesale prices would rise with adoption of RFID technology.

The above authors have discussed the inventory inaccuracy or lead-time expected impact of RFID technology on a supply chain's profit; however, quantitative assessments of the economical results of RFID adoption, not only in eliminating the misplacement but also in reducing leadtimes for ordering products, are limited in the existing literature. Our work contributes to the literature in that it jointly considers these two factors in the supply chain, and it has presented the perspective of service level, in both centralized and decentralized supply chains, stemming from misplaced inventory and lead-time with/without consideration of deploying RFID technology. Moreover, as a new technology, the cost of RFID tag limits its wide application, and supply chains lack a model on which to base the decision of whether or not to adopt RFID technology. In contrast, our work specifically focuses on the discussion of RFID tag cost thresholds that can improve the profit of both the centralized and decentralized supply chains with different service levels, and we find that a linear transfer payment coefficient strategy can make the players of decentralized supply chain to achieve a Pareto improvement.

\section{Model Assumptions and Notations}

We consider a supply chain where a supplier produces a single seasonal product and sells it to a retailer. The retailer sells the product in a store to end consumers. The retailer's ordering decision is made within a one-period newsvendor framework. Thus, as the information flows from retailer to supplier, the product flows in the reverse direction.

We assume that misplacement of inventory occurs immediately on delivery. Hence, as soon as the order is complete, $l(l=1-\alpha)$ proportion of the order gets misplaced in the store and only $\alpha(0<\alpha<1)$ proportion of the order is available to the end customers during the selling season. Customers or employees can misplace items on the shop floor or items can be misplaced in storage areas. In most real life settings, misplacement happens gradually over time. Therefore, according to the retailer's previous sales experience and statistics, a quantity of product $q$ ordered from the supplier can be divided into two portions: (1) $\alpha q$ is the portion available for sale to consumers and (2) $l q$ is the portion which is not available for sale due to misplacement. In this paper, we assume that, at the end of the period, all misplaced items will be found and will have a residual value. The adoption of the RFID technology has the potential to improve operational processes and provide real-time information update due to IoT's transparency and traceability; we assume that each SKU receives an RFID tag, so the availability proportion becomes $100 \%(\alpha=1)$. Since the implementation of RFID technology in supply chains is relatively new, the efficiency rate of the readers can be below $100 \%$ in some instances. This can also be incorporated into our model easily by assuming that availability goes to $\alpha<1$ instead of 1 .

We can easily understand the lead-time compression with RFID technology in the inset of Figure 1 . Setting $X$ is the demand within the period $[0, T]$, which is forecasted by the retailer before purchase time. We assume it follows a normal distribution whose normal density and distribution function are denoted by, respectively, $\phi(x)$ and $\Phi(x)$. The time from the retailer's order to receipt of the product is $T$; hence $T$ is the lead-time of the supply chain. If the supply chain does not adopt RFID technology, the retailer needs to order product at time 0 . The lead-time of the supply chain is $T$ at this moment, and the demand forecast is $X \sim$ $N\left(\mu, \sigma_{0}^{2}\right)$. On the contrary, if the supply chain establishes a new business model under IoT environment, an RFID tag will be placed on each product. The adoption of the RFID technology has the potential to increase the automation operational processes, reduce the time of manual operations, and improve the efficiency of manufacturing, transportation, storage, and other links; the retailer can order at time $t$, which means the lead-time is shortened to $T-t(0 \leq t \leq T)$, where $t$ is the amount of lead-time compression with RFID technology. At this moment, the demand forecast is $X \sim$ $N\left(\mu, \sigma_{t}^{2}\right)$. With lead-time compression, more information about product sales and demands will be available to the retailer, so the market demand forecast will be more accurate. We set that once the order time $t$ has been decided, the demand within $[0, T]$ period forecasted is $\mu$ and the forecast error standard deviation is $\sigma_{t}=\sigma_{0}+\left(\left(\sigma_{T}-\sigma_{0}\right) / T\right) t$. In fact, Chen and Chuang [13] use a similar form to this demand variance in their simulation study. $\sigma_{0}^{2}$ and $\sigma_{T}^{2}$ are the variance of market demand at time $t=0$ and at time $t=T$. We know that the variance $\sigma$ will decrease with the shortening of leadtime, so the assumption of $\sigma_{T}<\sigma_{0}$ is established. $f(x, 0)$ and $f(x, t)$ are the probability density function of $X$ at time 0 and time $t$, respectively, and $F(x, 0)$ and $F(x, t)$ are the cumulative density function of $X$ at time 0 and time $t$, respectively.

The notations used throughout this paper are as follows: $p$ : the unit product selling price; $s$ : the retailer's shortage (lost sales) cost per unit; $r$ : the retailer's inventory cost per unit; $m$ : the unit production cost; $w$ : the unit wholesale price; $c$ : the unit cost of RFID technology; q: the market demand of the retailers predicted; $v$ : the retailer's salvage value per unit.

In this paper, we assume that the service level of the supply chain (the available buying possibility of consumers) 


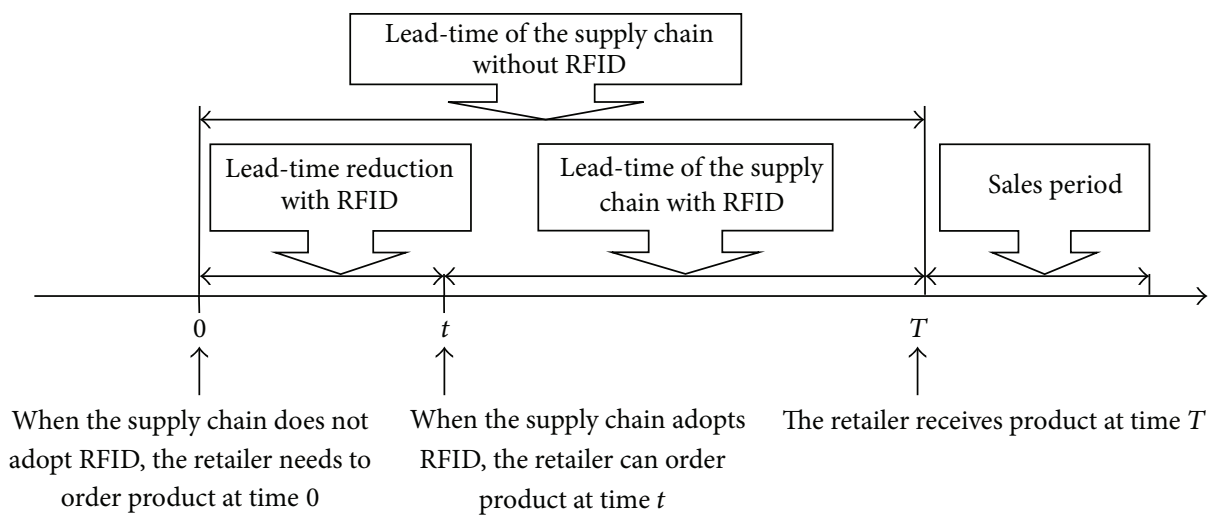

FIGURE 1: The lead-time reduction with adoption of RFID technology.

is greater than 0.5 in both the centralized and the decentralized cases with/without consideration of deploying RFID technology. If the service level is less than 0.5 , it means that the obtained rate of product is low and the supply chain needs to reorganize its practices.

\section{Centralized Supply Chain}

This section studies the centralized supply chain with a supplier and a retailer. It tackles the question of how to maximize the overall profit of the supply chain through decision-making. We study the profit of the supply chain with/without RFID technology and determine the cost-oftag threshold at which RFID technology investment becomes profitable with different service levels.

4.1. Without Adoption of RFID Technology. When the centralized supply chain does not adopt RFID technology, the retailer has to order $q$ at time 0 . However, portion $l q$ is misplaced. The centralized supply chain's profit $\pi_{C}(q, 0)$ without adoption of RFID technology will be given by

$$
\begin{aligned}
\pi_{C}(q, 0)= & p\left[\int_{0}^{\alpha q} x f(x, 0) d x+\int_{\alpha q}^{+\infty} \alpha q f(x, 0) d x\right] \\
& -r \int_{0}^{\alpha q}(\alpha q-x) f(x, 0) d x \\
& -s \int_{\alpha q}^{+\infty}(x-\alpha q) f(x, 0) d x+v l q-m q .
\end{aligned}
$$

In (1), the first and second terms are the expected profit of the centralized case, the third term is the price-cutting sales losses, the fourth term is the out-of-stock losses, the fifth term is the residual value of misplacements, and the sixth term is the cost of manufacture.
Performing first and second order differential on $q$ in (1), it can be derived that

$$
\begin{gathered}
\frac{\partial \pi_{C}(q, 0)}{\partial q}=\alpha\left[p \int_{\alpha q}^{+\infty} f(x, 0) d x-r \int_{0}^{\alpha q} f(x, 0) d x\right. \\
\left.\quad+s \int_{\alpha q}^{+\infty} f(x, 0) d x\right]+l v-m \\
=\alpha(p+s-v)+v-m-\alpha(p+s+r) F(\alpha q, 0), \\
\frac{\partial^{2} \pi_{C}(q, 0)}{\partial q^{2}}=-\alpha^{2}(p+s+r) f(\alpha q, 0)<0 .
\end{gathered}
$$

Through (2), it can be derived that profit function $\pi_{C}(q, 0)$ is concave in $q$. Therefore, the optimum $Q_{C 0}^{*}$ of (1) is $\partial \pi_{C}\left(Q_{C 0}^{*}, 0\right) / \partial q=0$. The optimal order quantity can be derived as follows:

$$
F\left(\alpha Q_{C 0}^{*}, 0\right)=\frac{\alpha(p+s-v)+v-m}{\alpha(p+s+r)} .
$$

Through (3), it can be derived that the misplacement causes the retailer to increase its optimal order quantity in order that $\alpha Q_{C 0}^{*}$ can satisfy the needs of the customers, because $F(x, 0) \geq 0$, so $F\left(\alpha Q_{C 0}^{*}, 0\right) \geq 0$. We can get Lemma 1 .

Lemma 1. Given $Q_{C 0}^{*}>0$, there exists a threshold value $\alpha \in\left[V_{\alpha}, 1\right]$ such that the profits of the centralized supply chain $\pi_{C}\left(\alpha Q_{C 0}^{*}, 0\right)>0$. Otherwise, if and only if $\alpha \in\left[0, V_{\alpha}\right]$ will make the profits of the centralized supply chain $\pi_{C}\left(\alpha Q_{C 0}^{*}, 0\right)<$ 0 , then the optimal strategy is not to place an order $\left(V_{\alpha}=\right.$ $(m-v) /(p+s-v))$.

Because $X \sim\left(\mu, \sigma^{2}\right),((X-\mu) / \sigma) \sim N(0,1)$, that is, $F\left(\alpha Q_{C 0}^{*}, 0\right)=\Phi\left(\left(\alpha Q_{C 0}^{*}-\mu\right) / \sigma_{0}\right)$, we can derive the optimal order quantity of the centralized supply chain $\alpha Q_{C 0}^{*}=\mu+$ $Z\left(S_{C 0}\right) \sigma_{0}$. According to Iyer and Bergen [12], the optimal service level of the centralized supply chain without RFID technology is defined as $S_{C 0}=\Phi\left(\left(\alpha Q_{C 0}^{*}-\mu\right) / \sigma_{0}\right)$, which means the available buying possibility of consumers, with the assumption in Section 2, obviously $0.5 \leq S_{C 0} \leq 1 . Z\left(S_{C 0}\right)$ 
is the $Z$ value of a standard normal distribution that generates a cumulative probability of $S_{C 0} . \Phi(x)$ is the monotonically increasing function. We know that the more the number of misplaced inventory, the smaller the bounded random variable $\alpha$, and the longer the lead-time, the bigger the demand forecast error $\sigma_{0}$. From the service level function $S_{C 0}=\Phi\left(\left(\alpha Q_{C 0}^{*}-\mu\right) / \sigma_{0}\right)$, we can derive Lemma 2 .

Lemma 2. In the centralized supply chain, the service level increases with the decrease of the misplaced inventory rate, but with the increase of the lead-time reduction.

By substituting the optimal order quantity into (1), the conclusion can be drawn that the maximum expected profit $\pi_{C}^{*}\left(\alpha Q_{C 0}^{*}, 0\right)$ of the centralized supply chain without adoption of RFID technology is

$$
\begin{aligned}
\pi_{C}^{*}\left(\alpha Q_{C 0}^{*}, 0\right)= & (p+s+r)\left[\mu \Phi\left(Z\left(S_{C 0}\right)\right)-\sigma_{0} \phi\left(Z\left(S_{C 0}\right)\right)\right] \\
& -\mu s .
\end{aligned}
$$

4.2. With Adoption of RFID Technology. When the supplier adopts RFID technology, then the cost of each product changes from $m$ to $m+c$. The retailer can use the radio frequency $(\mathrm{RF})$ reader to get the accurate inventory and order product at time $t$. We can derive the profits of the centralized supply chain $\pi_{C(q, t)}$ with adoption of RFID technology as follows:

$$
\begin{aligned}
\pi_{C}(q, t)= & p\left[\int_{0}^{q} x f(x, t) d x+\int_{q}^{+\infty} q f(x, t) d x\right] \\
& -r \int_{0}^{q}(q-x) f(x, t) d x \\
& -s \int_{q}^{+\infty}(x-q) f(x, t) d x-(m+c) q .
\end{aligned}
$$

In (5), the first and second terms are the expected profits of the centralized case, the third term is the price-cutting sales losses, the fourth term is out-of-stock losses, and the fifth term is the cost of production and RFID technology.

Doing first and second order differential on $q$ in (5), it can be derived that

$$
\begin{gathered}
\frac{\partial \pi_{C}(q, t)}{\partial q}=p \int_{q}^{+\infty} f(x, t) d x-r \int_{0}^{q} f(x, t) d x \\
\quad+s \int_{q}^{+\infty} f(x, t) d x-m-c \\
=(p+s-m-c)-(p+s+r) F(q, t), \\
\frac{\partial^{2} \pi_{C}(q, t)}{\partial q^{2}}=-(p+s+r) f(q, t)<0 .
\end{gathered}
$$

Through (6), it can be derived that $\pi_{C}(q, t)$ is the concave function of $q$; therefore, the optimum $Q_{C t}^{*}$ of (5) is $\partial \pi_{C}\left(Q_{C t}^{*}, t\right) / \partial q=0$. The optimal order quantity can be derived as follows:

$$
F\left(Q_{C t}^{*}, t\right)=\frac{p+s-m-c}{p+s+r} .
$$

We can derive Lemma 3 from (7).

Lemma 3. Given $Q_{C t}^{*}>0$, there exists a threshold value $c \in\left[0, U_{\gamma}\right]$ such that the profits of the centralized supply chain $\pi_{C}\left(Q_{C t}^{*}, t\right) \geq 0$. Otherwise, if and only if $c \in\left[U_{\gamma},+\infty\right]$ will make the profits of the centralized supply chain $\pi_{C}\left(Q_{C t}^{*}, t\right)<0$, then the optimal strategy is not adoption of RFID technology $\left(U_{\gamma}=p+s-m\right)$.

Because $X \sim\left(\mu, \sigma^{2}\right)$, so $((X-\mu) / \sigma) \sim N(0,1)$, that is, $F\left(Q_{C t}^{*}, t\right)=\Phi\left(\left(Q_{C t}^{*}-\mu\right) / \sigma_{t}\right)$, we can derive the optimal order quantity $Q_{C t}^{*}=\mu+Z\left(S_{C t}\right) \sigma_{t}$. In this section, the service level is $S_{C t}=\Phi\left(\left(Q_{C t}^{*}-\mu\right) / \sigma_{t}\right)=(p+s-m-c) /(p+s+r)$, and we can derive Lemma 4.

Lemma 4. In centralized supply chain, the service level increases with the decrease of the unit cost of RFID tag.

By substituting the optimal order quantity into (5), the conclusion can be drawn that the maximum expected profit $\pi_{C}^{*}\left(Q_{C t}^{*}, t\right)$ of the centralized supply chain with adoption of RFID technology is

$$
\begin{aligned}
\pi_{C}^{*}\left(Q_{C t}^{*}, t\right)= & (p+s+r)\left[\mu \Phi\left(Z\left(S_{C t}\right)\right)-\sigma_{t} \phi\left(Z\left(S_{C t}\right)\right)\right] \\
& -\mu s .
\end{aligned}
$$

4.3. The Difference between with and without RFID Technology in Service Level of the Centralized Supply Chain. By comparing the service level values of $S_{C 0}$ and $S_{C t}$, we can easily see the difference between with and without RFID technology in service level of the centralized supply chain in Theorem 5.

Theorem 5. The following findings hold for normal distributed demand. Only, with the normal sales rate $\alpha \in\left[V_{\alpha}, 1\right]$, will the centralized supply chain operate without adoption of RFID technology.

(1) When the unit cost of RFID technology is $c<U_{\alpha}$, adoption of the technology can enhance the service level of the centralized supply chain; namely, $S_{C t}>S_{C 0}\left(U_{\alpha}=\right.$ $(l / \alpha)(m-v))$.

(2) When the unit cost of RFID technology is $U_{\alpha} \leq c \leq U_{\gamma}$, adoption of the technology can lower the service level of the centralized supply chain; namely, $S_{C t} \leq S_{C 0}$.

When the centralized supply chain adopts RFID technology, it can increase the service level through eliminating the misplaced inventory and reducing the lead-time, but the extra cost of RFID tag will also decrease the service level. The supply chain will choose the appropriate service level to balance the relationship between the shortage cost and pricecutting sales cost. If the RFID tag cost is in a range, such as $c \in\left[0, U_{\alpha}\right)$, the service level of the supply chain can be 
improved, and the supply chain can maintain or lower the service level according to its actual situation to get a larger profit. But when the RFID tag cost is in the other range, such as $c \in\left[U_{\alpha}, U_{\gamma}\right]$, the positive effect on service level caused by misplaced inventory elimination and the lead-time reduction cannot balance the negative effect of the over high RFID tag cost, in this situation, the service level will decrease. The service level can be maintained or enhanced according to the actual operations of the centralized supply chain.

4.4. Decision-Making on RFID Technology Investment of the Centralized Supply Chain. For the centralized supply chain with a supplier and a retailer, there are two choices.

(1) Without adoption of RFID technology, the supply chain can avoid its cost. However, it will suffer the loss caused by misplaced inventory and too long leadtimes of supply chain.

(2) With adoption of RFID technology, lead-times can be shortened and misplaced inventory can be eliminated. However, the supply chain must be able to afford the cost of RFID technology.

We can get the decision-making on RFID investment in the centralized supply chain from Theorem 6.

Theorem 6. The following findings hold for normal distributed demand. Only, with the threshold value $\alpha \in\left[V_{\alpha}, 1\right]$, will the centralized supply chain operate without adoption of RFID technology.

(1) When the service level of the centralized supply chain is enhanced with RFID technology, the profit of the centralized case will increase if and only if $c \leq$ $\min \left(U_{\alpha}, U_{\beta}\right)$. Otherwise, it decreases: $\left(U_{\beta}=(l / \alpha)(m-\right.$ $\left.v)+\left((p+s+r)\left[\sigma_{0} \phi\left(Z\left(S_{C 0}\right)\right)-\sigma_{t} \phi\left(Z\left(S_{C t}\right)\right)\right] / \mu\right)\right)$.

(2) When the service level of the centralized supply chain is lowered with RFID technology, the profit of the centralized case will increase if and only if $U_{\alpha} \leq c \leq$ $\min \left(U_{\beta}, U_{\gamma}\right)$. Otherwise, it decreases.

The findings of Theorems 5 and 6 indicate that the centralized supply chain has more incentives to adopt the new technology as the mean of service level or profit or both increases. Hence, Figure 2 shows if the RFID tag price in some regions, the greatest benefits from RFID technology accrue to centralized supply chain under low inventory availability, under long lead-time, and in expectation of higher service level and profit. And we also find the trends of service level and profits are different with different RFID tag prices.

\section{Decentralized Supply Chain}

This section studies the decentralized supply chain with a supplier and a retailer. We assume that the supplier, as a Stackelberg leader, announces the wholesale price $w$ to the retailer, and the retailer as the follower orders product quantity, taking into consideration the wholesale price and the forecast demand of the market before season. We study the profit of each supply chain player with/without deploying RFID technology and determine the cost-of-tag threshold at which RFID technology investment becomes profitable with different service levels.

5.1. Without Adoption of RFID Technology. When the decentralized supply chain does not adopt RFID technology, the retailer has to order $q$ based on the wholesale price $w$ at time 0 . However, the item product $l q$ is misplaced. Taking $\pi_{D r}(q, 0)$, $\pi_{D s}(q, 0)$, and $\pi_{D}(q, 0)$ as the expected profit of the retailer, supplier, and decentralized supply chain without adoption of RFID technologywill be given by

$$
\begin{aligned}
& \pi_{D r}(q, 0)= p\left[\int_{0}^{\alpha q} x f(x, 0) d x+\int_{\alpha q}^{+\infty} \alpha q f(x, 0) d x\right] \\
&-r \int_{0}^{\alpha q}(\alpha q-x) f(x, 0) d x \\
&-s \int_{\alpha q}^{+\infty}(x-\alpha q) f(x, 0) d x+v l q-w q \\
& \pi_{D s}(q, 0)=(w-m) q, \\
& \pi_{D}(q, 0)=\pi_{D r}(q, 0)+\pi_{D s}(q, 0) .
\end{aligned}
$$

Based on the same idea as shown in Section 4.1, the optimal order quantity $Q_{D 0}^{*}$ of (9) can be derived as follows:

$$
F_{\left(\alpha Q_{D 0}^{*}, 0\right)}=\frac{\alpha(p+s-v)+v-w}{\alpha(p+s+r)} .
$$

Through (12), it can be derived that the misplaced inventory causes the retailer to increase its optimal order quantity, in order that $\alpha Q_{D 0}^{*}$ can satisfy the needs of the consumers, because $F_{(x, 0)} \geq 0$, so $F_{\left(\alpha Q_{D 0}^{*}, 0\right)} \geq 0$. We can get the retailer's order strategy from Lemma 7.

Lemma 7. Given $Q_{D 0}^{*}>0$, there exists a threshold value $\alpha \in\left[V_{\alpha}^{\prime}, 1\right]$ such that the retailer's profit $\pi_{D r}\left(\alpha Q_{D 0}^{*}, 0\right) \geq 0$. Otherwise, if and only if $\alpha \in\left[0, V_{\alpha}^{\prime}\right]$ will make the retailer's profit $\pi_{D r}\left(\alpha Q_{D 0}^{*}, 0\right)<0$, then the optimal strategy is not to place an $\operatorname{order}\left(V_{\alpha}^{\prime}=(w-v) /(p+s-v)\right)$.

We can derive the optimal order quantity of the decentralized supply chain $\alpha Q_{D 0}^{*}=\mu+Z\left(S_{D 0}\right) \sigma_{0}$. Obviously the optimal service level of the decentralized supply chain without RFID technology is $S_{D 0}=\Phi\left(\left(\alpha Q_{D 0}^{*}-\mu\right) / \sigma_{0}\right)\left(0.5 \leq S_{D 0} \leq 1\right)$. $Z\left(S_{D 0}\right)$ is the $Z$ value of a standard normal distribution that generates a cumulative probability of $S_{D 0}$. From the service level function $S_{D 0}=\Phi\left(\left(\alpha Q_{D 0}^{*}-\mu\right) / \sigma_{0}\right)$, we can derive Lemma 8.

Lemma 8. In the decentralized supply chain, the service level increases with the decrease of the misplaced inventory rate, but with the increase of the lead-time reduction.

As the retailer's optimal order quantity determines the order of the decentralized supply chain, substituting the optimal order quantity into (9), (10), and (11), we have the 

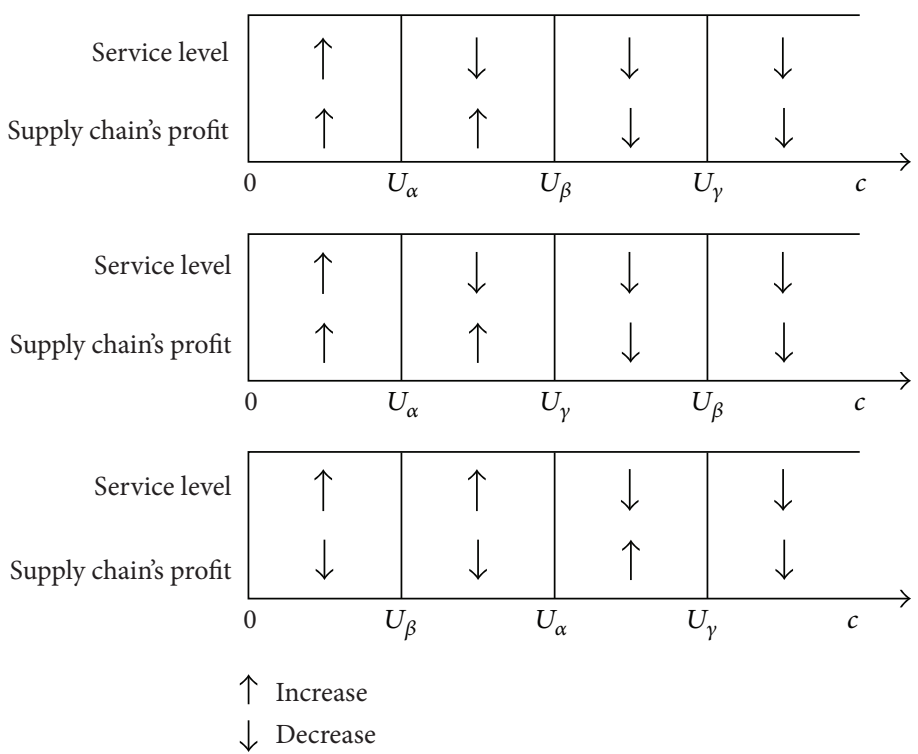

FIGURE 2: Service level and profit changes of the centralized supply chain with different costs of RFID tag.

maximum expected profit of the retailer, supplier, and decentralized supply chain without adoption of RFID technology, respectively, recorded as $\pi_{D r}^{*}\left(\alpha Q_{D 0}^{*}, 0\right), \pi_{D s}^{*}\left(\alpha Q_{D 0}^{*}, 0\right)$, and $\pi_{D}^{*}\left(\alpha Q_{D 0}^{*}, 0\right)$ :

$$
\begin{aligned}
\pi_{D r}^{*}\left(\alpha Q_{D 0}^{*}, 0\right)= & (p+s+r)\left[\mu \Phi\left(Z\left(S_{D 0}\right)\right)-\sigma_{0} \phi\left(Z\left(S_{D 0}\right)\right)\right] \\
& -\mu s, \\
\pi_{D s}^{*}\left(\alpha Q_{D 0}^{*}, 0\right)=\frac{(w-m)}{\alpha}\left(\mu+Z\left(S_{D 0}\right) \sigma_{0}\right), & (14) \\
\pi_{D}^{*}\left(\alpha Q_{D 0}^{*}, 0\right)= & \pi_{D r}^{*}\left(\alpha Q_{D 0}^{*}, 0\right)+\pi_{D s}^{*}\left(\alpha Q_{D 0}^{*}, 0\right) \\
= & (p+s+r)\left[\mu \Phi\left(Z\left(S_{D 0}\right)\right)-\sigma_{0} \phi\left(Z\left(S_{D 0}\right)\right)\right] \\
& -\mu s+\frac{(w-m)}{\alpha}\left(\mu+Z\left(S_{D 0}\right) \sigma_{0}\right) .
\end{aligned}
$$

5.2. With Adoption of RFID Technology. When the supplier adopts RFID technology, then the cost of each product changes from $m$ to $m+c$. The retailers can order at time $t$, taking $\pi_{D r}(q, t), \pi_{D s}(q, t)$, and $\pi_{D}(q, t)$ as the expected profit of the retailer, supplier, and decentralized supply chain; we have

$$
\begin{aligned}
& \pi_{D r}(q, t)= p\left[\int_{0}^{q} x f(x, t) d x+\int_{q}^{+\infty} q f(x, t) d x\right] \\
&-r \int_{0}^{q}(q-x) f(x, t) d x \\
&-s \int_{q}^{+\infty}(x-q) f(x, t) d x-w q, \\
& \pi_{D s}(q, t)=(w-m-c) q, \\
& \pi_{D}(q, t)=\pi_{D r}(q, t)+\pi_{D s}(q, t) .
\end{aligned}
$$

Based on the same idea as shown in Section 4.2, the optimal order quantity $Q_{D t}^{*}$ of (16) can be derived as follows:

$$
F_{\left(Q_{D t}^{*}, t\right)}=\frac{p+s-w}{p+s+r}
$$

We can derive Lemma 9 from (7).

Lemma 9. The optimal order quantity of the decentralized supply chain with RFID technology is always greater than 0; that is, $Q_{D t}^{*}>0$, such that the retailer's profit $\pi_{D r}\left(Q_{D t}^{*}, t\right) \geq 0$; then the optimal strategy is pushing its supplier to adopt RFID technology.

The optimal order quantity of the decentralized supply chain with RFID technology is $Q_{D t}^{*}=\mu+Z\left(S_{D t}\right) \sigma_{t}$. In this section, the service level is $S_{D t}=\Phi\left(\left(Q_{D t}^{*}-\mu\right) / \sigma_{t}\right)=(p+s-$ $w) /(p+s+r)$; we can derive Lemma 10 .

Lemma 10. In the decentralized supply chain, the unit cost of RFID tag does not affect the service level.

As the retailer's optimal order quantity determines the order of the decentralized supply chain, substituting the optimal order quantity into (16), (17), and (18), we have the maximum expected profit of the retailer, supplier, and decentralized supply chain with adoption of RFID technology, respectively, recorded as $\pi_{D r}^{*}\left(Q_{D t}^{*}, t\right), \pi_{D s}^{*}\left(Q_{D t}^{*}, t\right)$, and $\pi_{D}^{*}\left(Q_{D t}^{*}, t\right)$ :

$$
\begin{aligned}
\pi_{D r}^{*}\left(Q_{D t}^{*}, t\right)= & (p+s+r)\left[\mu \Phi\left(Z\left(S_{D t}\right)\right)-\sigma_{t} \phi\left(Z\left(S_{D t}\right)\right)\right] \\
& -\mu s
\end{aligned}
$$$$
\pi_{D s}^{*}\left(Q_{D t}^{*}, t\right)=(w-m-c)\left(\mu+Z\left(S_{D t}\right) \sigma_{t}\right),
$$ 


$$
\begin{aligned}
\pi_{D}^{*}\left(Q_{D t}^{*}, t\right)= & \pi_{D r}^{*}\left(Q_{D t}^{*}, t\right)+\pi_{D s}^{*}\left(Q_{D t}^{*}, t\right) \\
= & (p+s+r)\left[\mu \Phi\left(Z\left(S_{D t}\right)\right)-\sigma_{t} \phi\left(Z\left(S_{D t}\right)\right)\right] \\
& -\mu s+(w-m-c)\left(\mu+Z\left(S_{D t}\right) \sigma_{t}\right) .
\end{aligned}
$$

5.3. The Difference between with and without RFID Technology in Service Level of the Decentralized Supply Chain. By comparing the service level values of $S_{D 0}$ and $S_{D t}$, we can easily find the difference between with and without RFID technology in service level of the decentralized supply chain in Theorem 11.

Theorem 11. The following findings hold for normal distributed demand. Only, with the normal sales rate $\alpha \in$ $\left[V_{\alpha}^{\prime}, 1\right]$, will the decentralized supply chain operate without adoption of RFID technology. When the supplier adopts the RFID technology in the decentralized supply chain, the service level will be enhanced.

RFID technology will increase the retailer's service level by eliminating the misplaced inventory and reducing the lead-time, but the supplier undertakes the extra cost of RFID tag; thus the service level will increase. Then the retailer can choose to maintain or probably reduce its service level according to the actual situation to get more benefits.

\subsection{Decision-Making on RFID Technology Investment of the Decentralized Supply Chain}

\subsubsection{The Impact of Adopting RFID Technology on the Profit of the Decentralized Supply Chain}

Proposition 12. When the normal sales rate $\alpha \in\left[V_{\alpha}^{\prime}, 1\right]$ and the unit cost of RFID tag $c \in\left(0, U_{\beta}^{\prime}\right)$, the profit of the decentralized supply chain will increase with adoption of RFID technology. Otherwise, it decreases: $\left(U_{\beta}^{\prime}=(\beta+\right.$ $\left.(w-m)\left(Z\left(S_{D t}\right) \sigma_{t}-Z\left(S_{D 0}\right) \sigma_{0} / \alpha\right)\right) /\left(\mu+Z\left(S_{D t}\right) \sigma_{t}\right)$ and $\beta=$ $\left.(\mu l / \alpha)(m-v)+(p+s+r)\left[\sigma_{0} \phi\left(Z\left(S_{D 0}\right)\right)-\sigma_{t} \phi\left(Z\left(S_{D t}\right)\right)\right]\right)$.

\subsubsection{The Impact of Adopting RFID Technology on the Retailer's Profit}

Proposition 13. When the profit of the decentralized supply chain increases with adoption of RFID technology, the retailer's profit will always increase. Otherwise, it decreases.

\subsubsection{The Impact of Adopting RFID Technology on the Sup- plier's Profit}

Proposition 14. When the normal sales rate $\alpha \in\left[V_{\mu}, 1\right]$ and the unit cost of RFID tag $c \in\left(0, U_{\alpha}^{\prime}\right)$, the supplier's profit will increase. Otherwise, it decreases: $\left(U_{\alpha}^{\prime}=((\mu l / \alpha)(m-w)+(w-\right.$ $\left.m)\left(Z\left(S_{D t}\right) \sigma_{t}-Z\left(S_{D 0}\right) \sigma_{0} / \alpha\right)\right) /\left(\mu+Z\left(S_{D t}\right) \sigma_{t}\right)<U_{\beta}^{\prime}$ and $V_{\mu}=$ $\left.\left(\mu+Z\left(S_{D 0}\right) \sigma_{0}\right) /\left(\mu+Z\left(S_{D t}\right) \sigma_{t}\right)\right)$.
From the above three propositions, we find that the retailer is better off if and only if the decentralized supply chain is better off with adoption of RFID technology by supplier. As a consequence, when the supplier bears the cost of RFID tag, the retailer gets the benefits from "spillover effect" of misplacement elimination and lead-time compression. There are three cases: (1) both the supplier and the retailer benefit from an investment in RFID, (2) only the retailer benefits from an investment in RFID, but the profit of decentralized supply chain also increases, and (3) no party benefits from an investment in RFID.

We can get the decision-making on RFID investment in the decentralized supply chain from Theorem 15 .

Theorem 15. The following findings hold for normal distributed demand.

(1) When the normal sales rate $\alpha \in\left[V_{\mu}, 1\right]$ and the unit cost of RFID $\operatorname{tag} c \in\left(0, U_{\alpha}^{\prime}\right)$, each player's profit will increase with adoption of RFID technology in the decentralized supply chain.

(2) When the normal sales rate $\alpha \in\left[V_{\mu}, 1\right]$ and the unit cost of RFID tag $c \in\left(U_{\alpha}^{\prime}, U_{\beta}^{\prime}\right)$ or when the normal sales rate $\alpha \in\left[V_{\alpha}^{\prime}, V_{\mu}\right)$ and the unit cost of RFID $\operatorname{tag} c \in$ $\left(0, U_{\beta}^{\prime}\right)$, the profit of the decentralized supply chain and the retailer increases, while the supplier's profit reduces with adoption of RFID technology. The linear transfer payment coefficient strategy can coordinate and achieve a Pareto improvement in this case.

In Figure 3, we can find that the trends of service level and profit are different with different RFID tag prices and understand the above analyses more clearly.

5.5. Coordination. According to the Theorem 15, we find an interesting phenomenon that the retailer's profit increases, while the supplier's profit decreases with adoption of RFID technology, but the profit of the decentralized supply chain also increases. The reasons of the supplier's profit decrease with RFID technology as follows: firstly, the supplier pays the cost of RFID tag; secondly, with the misplaced inventory elimination and the lead-time reduction, the retailer's optimal order quantity $Q_{D t}^{*}=\mu+Z\left(S_{D t}\right) \sigma_{t}$ will decrease. In order to prevent the risk of supply-strand breaking and promote the supplier adopting RFID technology to increase the service level and profit of the decentralized supply chain, we should coordinate this phenomenon with a contract. In this paper, we find that the linear transfer payment coefficient strategy can be used by the retailer to coordinate each player in the decentralized system with RFID.

Assume that the retailer transfers a part of the increasing profit $\theta \Delta_{D r}(0 \leq \theta \leq 1)$ to the supplier, compensating its losses caused by adoption of RFID technology. If not only the retailer's profit is incremented by $(1-\theta) \Delta_{D r} \geq 0$, but also the supplier's profit is incremented by $\Delta_{D s}+\theta \Delta_{D r} \geq 0$, 


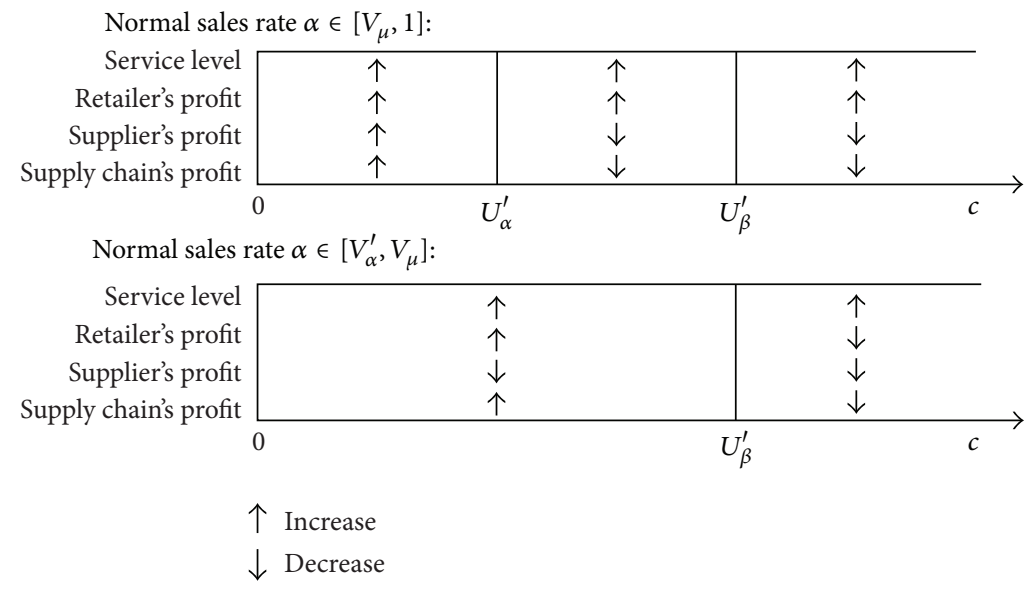

FIGURE 3: Service level and profit changes of the decentralized supply chain with different cost of RFID tag.

the players can achieve a Pareto improvement. We come to the conclusion as follows:

$$
\begin{aligned}
\Delta_{D s}+\theta \Delta_{D r}= & \left\{\frac{\mu l}{\alpha}(m-w)+(w-m)\right. \\
& \times\left(Z\left(S_{D t}\right) \sigma_{t}-\frac{Z\left(S_{D 0}\right) \sigma_{0}}{\alpha}\right) \\
& \left.-c\left(\mu+Z\left(S_{D t}\right) \sigma_{t}\right)\right\} \\
+ & \theta\left\{\frac{\mu l}{\alpha}(w-v)+(p+s+r)\right. \\
& \left.\times\left[\sigma_{0} \phi\left(Z\left(S_{D 0}\right)\right)-\sigma_{t} \phi\left(Z\left(S_{D t}\right)\right)\right]\right\} \geq 0 .
\end{aligned}
$$

From (23), we can derive the coordination rules in Theorem 16.

Theorem 16. The following findings hold for normal distributed demand.

(1) When the normal sales rate $\alpha \in\left[0, V_{\mu}\right)$, thus $Q_{D t}^{*}<$ $Q_{D 0}^{*}$; the coefficient of linear transfer payment should satisfy $\theta \in\left[U_{\theta}, 1\right]$; then each player's profit will increase with adoption of RFID technology: $\left(U_{\theta}=(\alpha(w-\right.$ $\left.\left.m)\left(Q_{D 0}^{*}-Q_{D t}^{*}\right)+\alpha c\left(\mu+Z\left(S_{D t}\right) \sigma_{t}\right)\right) /(\alpha \beta+\mu l(w-m))\right)$.

(2) When the normal sales rate $\alpha \in\left[V_{\mu}, 1\right]$, thus $Q_{D t}^{*} \geq$ $Q_{D 0}^{*}$; the coefficient of linear transfer payment should satisfy $\theta \in\left[0, U_{\theta}\right]$; then each player's profit will increase with adopting RFID technology.

Thus both partied achieve a Pareto improvement, and the linear transfer payment coefficient strategy will ensure a coordination of the decentralized system with adoption of RFID technology.

\section{Numerical Examples}

To illustrate the proposed models, we give numerical examples as follows. According to Camdereli and Swaminathan [20], as well as Chen and Chuang [13], we suppose $\mu=5000$ units, $\sigma_{0}=2000$ units, $\sigma_{T}=200$ units, $T=10$ weeks, $p=6$ dollars/per unit, $s=4$ dollars/per unit, $r=1$ dollar/per unit, $m=2$ dollars/per unit, $w=3$ dollars/per unit, and $v=0.5$ dollar/per unit. The simulation data used for carrying out these numerical computations are assumed to represent real-world conditions as closely as possible.

6.1. The Difference between with and without RFID Technology in Service Level of the Supply Chain. From Figures 4 and 5, we know that the unit price of RFID tag will influence the service level in the centralized supply chain, but it does not have effect on the service level in the decentralized supply chain. And we can directly demonstrate the conclusions of the Theorems 5 and 11.

6.2. Impact of Misplaced Inventory and Lead-Time on the Maximum Costs of RFID Tag. Consider the supply chain can bear maximum costs of RFID tag under the lead-time reduction $t \in[0,10]$ with three different normal sales rates, such as $\alpha=0.8, \alpha=0.9$, and $\alpha=1$. According to the Theorems 6 and 15, we get Figures 6 and 7 with Matlab7.0. We find that, for both of the centralized supply chain and the decentralized supply chain, the supply chain can bear the maximum costs of RFID tag increase with the decrease of the normal sales rate, but with the increase of the lead-time reduction.

Then we compare Figure 6 with Figure 7 and find that the centralized case is more efficient than the decentralized case. We find that the maximum costs of RFID tag which the centralized case bearing is much more than the decentralized case bearing when the normal sales rate and the lead-time are both same. Now the RFID tag price is still expensive; the centralized case is more suitable for adopting RFID technology. If the supply chain has acapital constraint in 


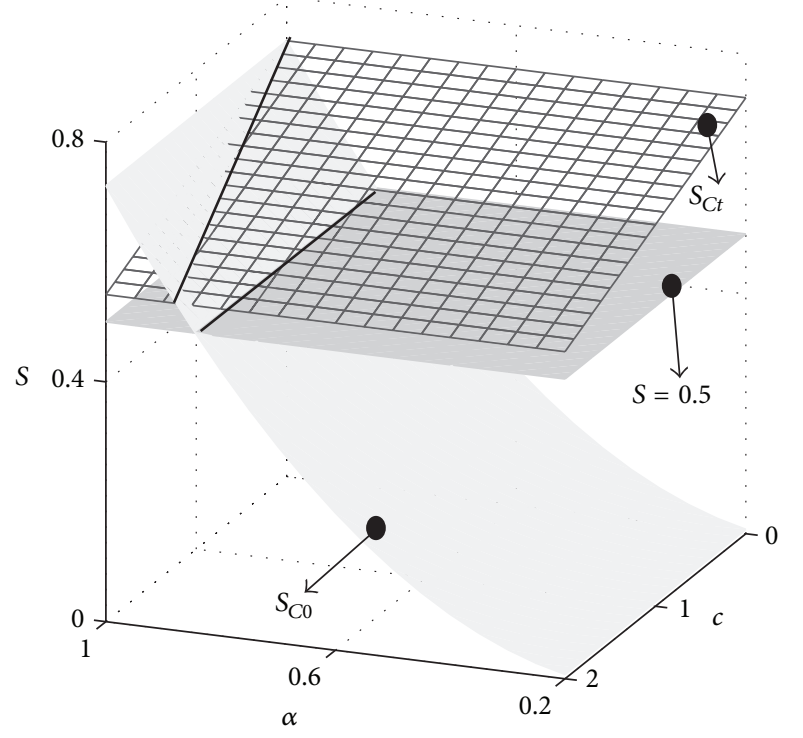

FIGURE 4: Service level change of the centralized supply chain with/without RFID technology.

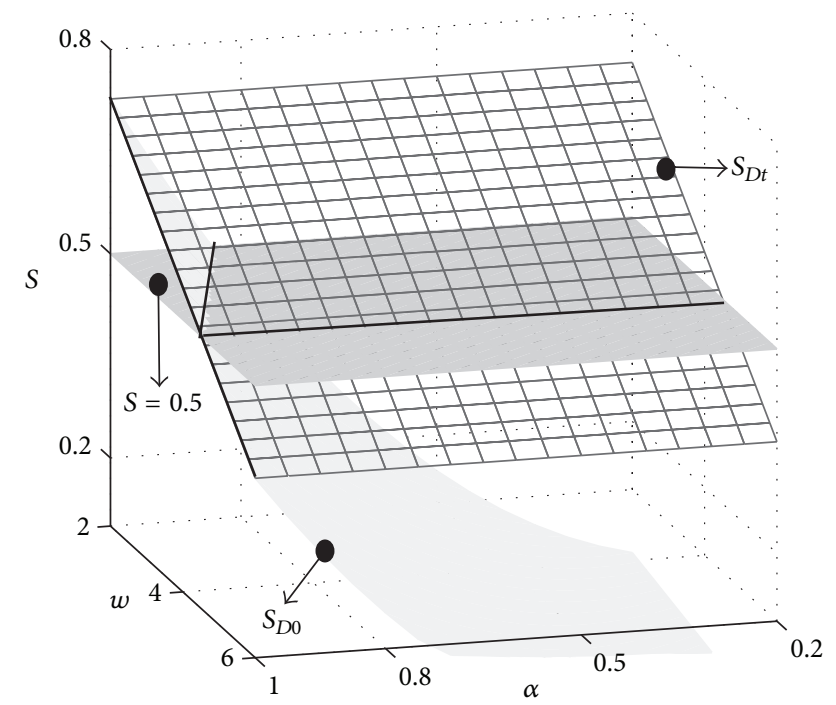

FIGURE 5: Service level change of the decentralized supply chain with/without RFID technology.

adoption of RFID technology, there is a solution that turns the supply chain into the centralized case.

6.3. Impact of Adopting RFID Technology on the Players' Profit of the Decentralized Supply Chain. Suppose the lead-time reduction is $t$ (from 0 to 10 ) and the unit cost of RFID tag is $c=0.2$; we investigate the each player's profit variation with adoption of RFID technology by the decentralized supply chain with three different normal sales rates, such as $\alpha=0.8$, $\alpha=0.9$, and $\alpha=1$, which are shown in Figure 8. We find that each player's profit increment increases with the decrease of the normal sales rate, but with the increase of the lead-time reduction. And we can directly demonstrate

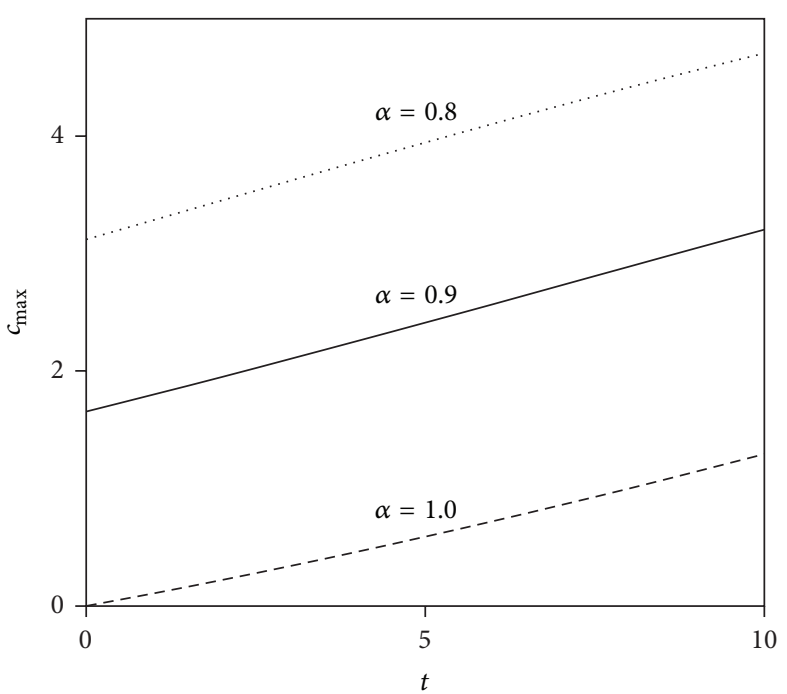

FIgURE 6: The maximum costs of RFID tag in the centralized supply chain.

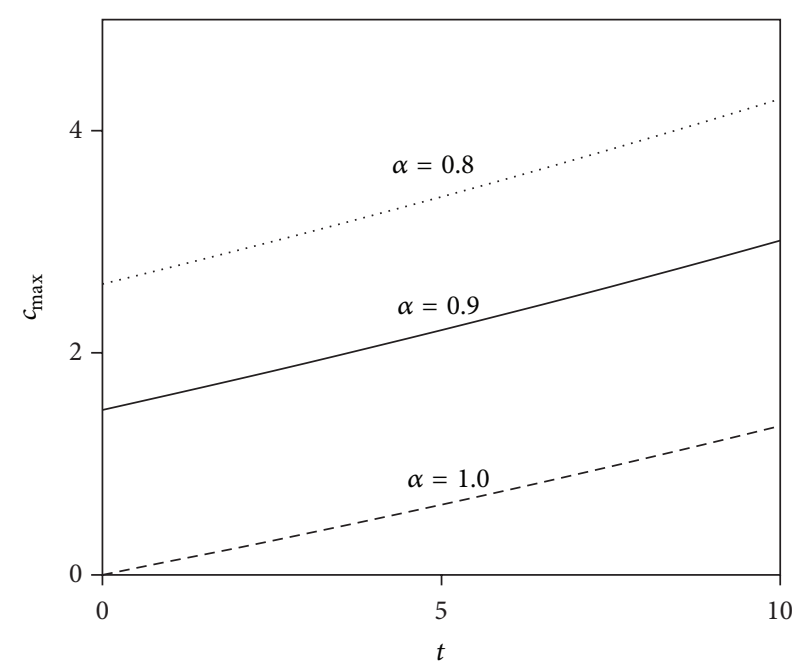

FIGURE 7: The maximum costs of RFID tag in the decentralized supply chain.

the conclusions of Proposition 13; if the profit increment of the decentralized supply chain is greater than zero, then the retailer's profit increment is always greater than zero. Then we have found that when the profit increment of the decentralized supply chain is greater than zero while the supplier's profit increment is less than zero, the linear transfer payment coefficient strategy can coordinate the supply chain.

6.4. Coordination. We assume the unit cost of RFID tag is $c=0.2$, the normal sales rate is $\alpha=0.8$, and the lead-time reduction is $t=5$. Thus $V_{\mu}=0.991>\alpha=0.8$, so we take the coefficient of linear transfer payment $\theta \in\left(U_{\theta}, 1\right)$ into consideration (the case that the services level $\alpha \in\left[V_{\mu}, 1\right]$ and coefficient of linear transfer payment $\theta \in\left(0, U_{\theta}\right)$ can be solved in the same way). 


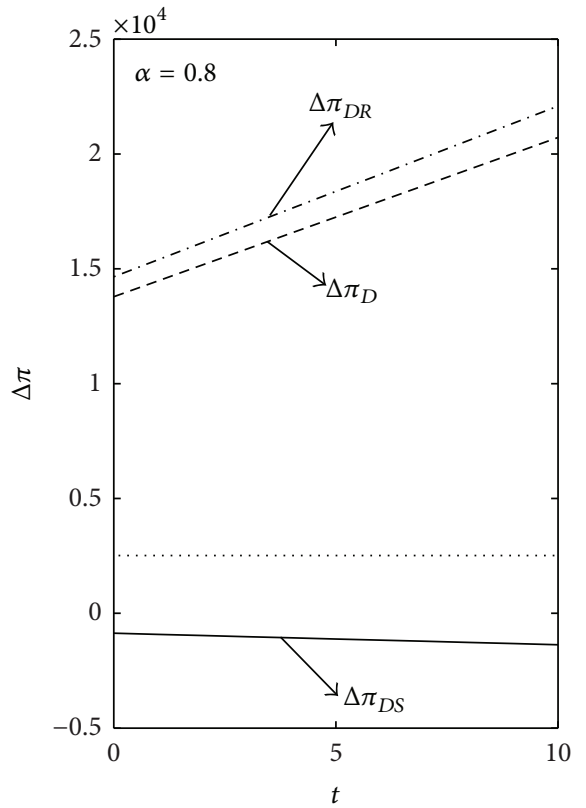

(a)

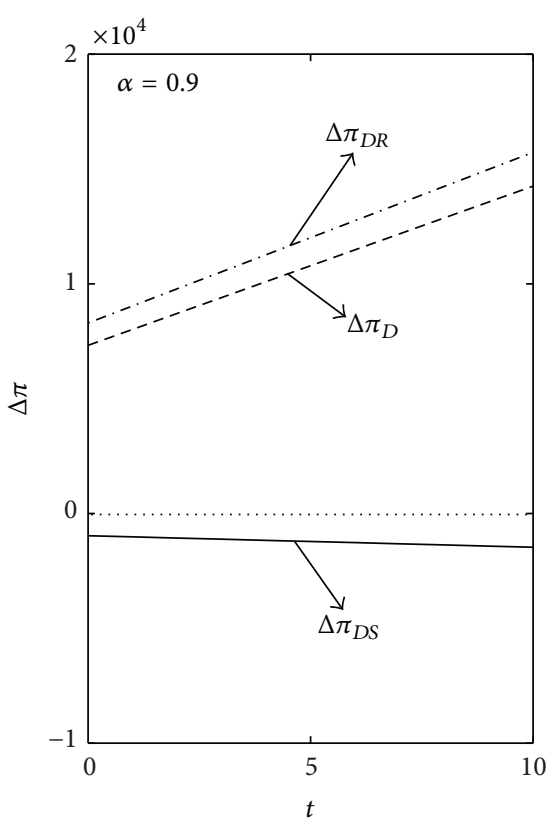

(b)

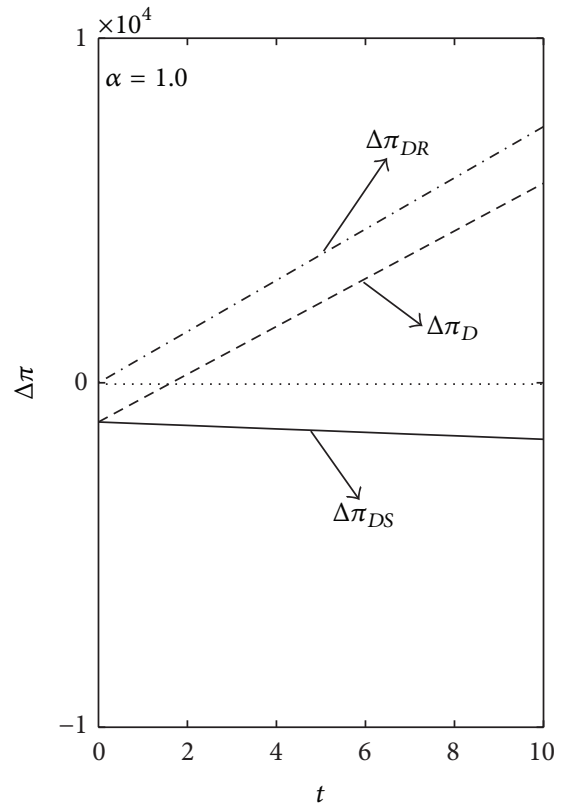

(c)

FIGURE 8: Impact of adopting RFID technology on the profit of decentralized supply chain and its players.

With the coefficient of linear transfer payment $\theta \in[0,1]$, the profit variation of the decentralized supply chain and its members are shown in Table 2. We find that when the coefficient of linear transfer payment $\theta \geq 0.3403$, each player's profit will increase at the same time with adoption of RFID technology by the decentralized supply chain. Then the decentralized case achieves Pareto improvement.

\section{Conclusions}

As a new technology, RFID can solve many problems in supply chain management. However, its cost limits its wide application, and supply chains lack a model on which to base the decision of whether or not to adopt RFID technology. This paper considers a two-echelon supply with a supplier and a retailer, which suffers from the misplaced inventory and the lead-time, and assumes that the market demand forecast error varies with lead-time reduction. Considering the fact that RFID technology can eliminate the misplaced inventory and compress the lead-time of a supply chain, we present a perspective of service level and use a newsvendor model to study the difference of service level and profit of the centralized/decentralized supply chains with adoption of RFID technology.

Our results first showed that, in both centralized and decentralized supply chain, the service level not only increases with the decrease of the number of misplaced product but also increases with the increase of the lead-time reduction.

Secondly, there is one distinguishing feature of our study that we validated the adoption of RFID technology affecting the service level of the supply chain. We find that whether adoption of RFID improves the service level depends on the cost of the RFID tag in the centralized supply chain, but it improves the service level in the decentralized case regardless of the cost.

Thirdly, there exist the same cost-of-tag thresholds with different service levels in both the centralized and the decentralized cases. Furthermore, we prove that the linear transfer payment coefficient strategy can coordinate the decentralized supply chain with adoption of RFID technology, while the profit of supply chain and retailer increase but supplier's profit reduces.

It would be interesting to study the problem of technology adoption in multiple sales periods incorporating price markdowns between periods. Moreover, adding the fixed cost of the RFID technology in our paper is also a meaningful question. But the cost sharing of the RFID tag is not useful when there is a game between the players in the decentralized supply chain; the supplier will transfer the addition RFID cost through the wholesale price to the retailer (like [24]).

\section{Appendices}

\section{A. Derivation of (4)}

By substituting the optimal order quantity into (1), the conclusion can be drawn that the maximum expected profit $\pi_{C}^{*}\left(\alpha Q_{C 0}^{*}, 0\right)$ of the centralized supply chain without adoption of RFID technology is as follows:

$$
\begin{aligned}
\pi_{C}^{*}\left(\alpha Q_{C 0}^{*}, 0\right)= & p \alpha Q_{C 0}^{*}\left[1-F\left(\alpha Q_{C 0}^{*}, 0\right)\right]-r \alpha Q_{C 0}^{*} F\left(\alpha Q_{C 0}^{*}, 0\right) \\
& +s \alpha Q_{C 0}^{*}\left[1-F\left(\alpha Q_{C 0}^{*}, 0\right)\right]+v(1-\alpha) Q_{C 0}^{*}
\end{aligned}
$$


TABLE 2: The profit variation of the decentralized supply chain and its members with coefficient of linear transfer payment $\theta$ (from 0 to 1 ).

\begin{tabular}{lcccccc}
\hline$\theta$ & \multicolumn{2}{c}{ The retailer } & \multicolumn{2}{c}{ The supplier } & \multicolumn{2}{c}{ The supply chain } \\
& $\pi^{*}{ }_{\operatorname{Dr}(q, 5)}^{*}$ & $\Delta_{r}$ & $\pi^{*}{ }_{s(q, 5)}$ & $\Delta_{s}$ & $\pi^{*}{ }^{(q, 5)}$ & 14764.5 \\
0 & 10457.6 & 7184.3 & 4306.9 & -2444.9 & 14764.5 & 4739.4 \\
0.2 & 9020.7 & 5747.4 & 5743.8 & -1008.0 & 14764.5 & 4739.4 \\
0.4 & 7583.9 & 4310.6 & 7180.6 & 428.8 & 14764.5 & 4739.4 \\
0.6 & 6147.0 & 2873.7 & 8617.5 & 1865.7 & 14764.5 & 4739.4 \\
0.8 & 4710.2 & 1436.9 & 10054.3 & 3302.5 & 4739.4 \\
1 & 3273.3 & 0.0 & 11491.2 & 4739.4 & 4739.4 \\
\hline
\end{tabular}

$$
\begin{aligned}
& -m Q_{C 0}^{*}+(p+r) \int_{0}^{\alpha Q_{C 0}^{*}} x f(x, 0) d x \\
& -s \int_{\alpha Q_{C 0}^{*}}^{+\infty} x f(x, 0) d x \\
& =p \alpha Q_{C 0}^{*}\left[1-F\left(\alpha Q_{C 0}^{*}, 0\right)\right]-r \alpha Q_{C 0}^{*} F\left(\alpha Q_{C 0}^{*}, 0\right) \\
& +s \alpha Q_{C 0}^{*}\left[1-F\left(\alpha Q_{C 0}^{*}, 0\right)\right]+v(1-\alpha) Q_{C 0}^{*} \\
& -m Q_{C 0}^{*}-(p+s+r) \sigma_{0} \phi\left(Z\left(S_{C 0}\right)\right) \\
& +\mu(p+s+r) \Phi\left(Z\left(S_{C 0}\right)\right)-\mu s \\
& =\left[p+s+\frac{v l-m}{\alpha}\right]\left(\mu+Z\left(S_{\mathrm{C} 0}\right) \sigma_{0}\right) \\
& -\sigma_{0}(p+s+r) \\
& \times\left[Z\left(S_{C 0}\right) \Phi\left(Z\left(S_{C 0}\right)\right)+\phi\left(Z\left(S_{C 0}\right)\right)\right]-\mu s \\
& =\mu\left[p+s+\frac{v l-m}{\alpha}\right] \\
& +Z\left(S_{C 0}\right) \sigma_{0}\left[p+s+\frac{(1-\alpha) v-m}{\alpha}\right] \\
& -Z\left(S_{C 0}\right) \sigma_{0}(p+s+r) \\
& \times\left(\frac{\alpha p+\alpha s-\alpha v+v-m}{\alpha p+\alpha s+\alpha r}\right) \\
& -\sigma_{0}(p+s+r) \phi\left(Z\left(S_{C 0}\right)\right)-\mu s \\
& =\mu(p+s+r)\left(\frac{\alpha p+\alpha s-\alpha v+v-m}{\alpha p+\alpha s+\alpha r}\right) \\
& -\sigma_{0}(p+s+r) \phi\left(Z\left(S_{C 0}\right)\right)-\mu s \\
& =(p+s+r)\left[\mu \Phi\left(Z\left(S_{C 0}\right)\right)-\sigma_{0} \phi\left(Z\left(S_{C 0}\right)\right)\right] \\
& -\mu s \text {. }
\end{aligned}
$$

\section{B. Derivation of $(8)$}

By substituting the optimal order quantity into (5), the conclusion can be drawn that the maximum expected profit
$\pi_{C}^{*}\left(Q_{C t}^{*}, t\right)$ of the centralized supply chain with adoption of RFID technology is as follows:

$$
\begin{aligned}
& \pi_{C}^{*}\left(Q_{C t}^{*}, t\right)=p Q_{C t}^{*}\left[1-F\left(Q_{C t}^{*}, t\right)\right]-r Q_{C t}^{*} F\left(Q_{C t}^{*}, t\right) \\
& +s Q_{C t}^{*}\left[1-F\left(Q_{C t}^{*}, t\right)\right]-(m+c) Q_{C t}^{*} \\
& +(p+r) \int_{0}^{Q_{C t}^{*}} x f(x, t) d x-s \int_{Q_{C t}^{*}}^{+\infty} x f(x, t) d x \\
& =p Q_{C t}^{*}\left[1-F\left(Q_{C t}^{*}, t\right)\right]-r Q_{C t}^{*} F\left(Q_{C t}^{*}, t\right) \\
& +s Q_{C t}^{*}\left[1-F\left(Q_{C t}^{*}, t\right)\right]-(m+c) Q_{C t}^{*} \\
& -(p+s+r) \sigma_{t} \phi\left(Z\left(S_{C t}\right)\right) \\
& +\mu(p+s+r) \Phi\left(Z\left(S_{C t}\right)\right)-\mu s \\
& =(p+s-m-c)\left(\mu+Z\left(S_{C t}\right) \sigma_{t}\right)-\sigma_{t}(p+s+r) \\
& \times\left[Z\left(S_{C t}\right) \Phi\left(Z\left(S_{C t}\right)\right)+\phi\left(Z\left(S_{C t}\right)\right)\right]-\mu s \\
& =\mu(p+s-m-c)+Z\left(S_{C t}\right) \sigma_{t}(p+s-m-c) \\
& -Z\left(S_{C t}\right) \sigma_{t}(p+s+r)\left(\frac{p+s-m-c}{p+s+r}\right) \\
& -\sigma_{t}(p+s+r) \phi\left(Z\left(S_{C t}\right)\right)-\mu s \\
& =\mu(p+s+r)\left(\frac{p+s-m-c}{p+s+r}\right) \\
& -\sigma_{t}(p+s+r) \phi\left(Z\left(S_{C t}\right)\right)-\mu s \\
& =(p+s+r)\left[\mu \Phi\left(Z\left(S_{C t}\right)\right)-\sigma_{t} \phi\left(Z\left(S_{C t}\right)\right)\right] \\
& -\mu s \text {. }
\end{aligned}
$$

Proof of Theorem 6. In order to study the influence of the adoption of RFID technology on the profit of the centralized supply chain, we determine the decision strategy for adoption of RFID technology by comparing profit models of the supply chain with/without RFID technology. If $\Delta_{C}$ stands for the profit variation of the centralized supply chain 
with/without consideration of deploying RFID technology, it can be derived that

$$
\begin{aligned}
\Delta_{C}= & \pi_{C}^{*}\left(Q_{C t}^{*}, t\right)-\pi_{C}^{*}\left(\alpha Q_{C 0}^{*}, 0\right) \\
= & \left\{(p+s+r)\left[\mu \Phi\left(Z\left(S_{C t}\right)\right)-\sigma_{t} \phi\left(Z\left(S_{C t}\right)\right)\right]-\mu s\right\} \\
& -\left\{(p+s+r)\left[\mu \Phi\left(Z\left(S_{C 0}\right)\right)-\sigma_{0} \phi\left(Z\left(S_{C 0}\right)\right)\right]-\mu s\right\} \\
= & \frac{(1-\alpha) \mu}{\alpha}(m-v)+(p+s+r) \\
& \times\left[\sigma_{0} \phi\left(Z\left(S_{C 0}\right)\right)-\sigma_{t} \phi\left(Z\left(S_{C t}\right)\right)\right]-\mu c .
\end{aligned}
$$

We make a function $y_{C}=(\mu l / \alpha)(m-v)+(p+s+$ $r)\left[\sigma_{0} \phi\left(Z\left(S_{C 0}\right)\right)-\sigma_{t} \phi\left(Z\left(S_{C t}\right)\right)\right]$; then we discuss it in two different conditions.

(A) When the service level is $0.5 \leq S_{C 0}<S_{C t}$, which means $0 \leq Z\left(S_{C 0}\right)<Z\left(S_{C t}\right)$, then $\phi\left(Z\left(S_{C 0}\right)\right)>$ $\phi\left(Z\left(S_{C t}\right)\right)>0$. Also, because $\sigma_{0}>\sigma_{t}>0$ and $\sigma_{0} \phi\left(Z\left(S_{\mathrm{C} 0}\right)\right)-\sigma_{t} \phi\left(Z\left(S_{C t}\right)\right)>0$, then $y_{C}>0$. When the cost of RFID $\operatorname{tag}$ is $c \leq \min \left\{U_{\alpha}, U_{\beta}\right\}$, the overall profit of the supply chain can be increased.

(B) When the service level is $0.5 \leq S_{C t} \leq S_{C 0}$, which means $0<Z\left(S_{C t}\right) \leq Z\left(S_{C 0}\right)$, then $0<\phi\left(Z\left(S_{C 0}\right)\right) \leq$ $\phi\left(Z\left(S_{C t}\right)\right)$. Also, because $\sigma_{0}>\sigma_{t}>0$, we cannot determine whether $\sigma_{0} \phi\left(Z\left(S_{\mathrm{C} 0}\right)\right)$ or $\sigma_{t} \phi\left(Z\left(S_{C t}\right)\right)$ is larger. When $\phi\left(Z\left(S_{C t}\right)\right) \leq\left((1-\alpha) \mu / \alpha(p+s+r) \sigma_{t}\right)(m-$ $v)+\left(\sigma_{0} / \sigma_{t}\right) \phi\left(Z\left(S_{C 0}\right)\right)$, it can be ensured that $y_{C} \geq 0$ when the cost of adopting RFID technology is $U_{\alpha} \leq$ $c \leq \min \left(U_{\beta}, U_{\gamma}\right)$; thus, the overall profits of the supply chain will increase.

\section{Derivation of (13)}

By substituting the optimal order quantity into (9), we have the maximum expected profit of the retailer without adoption of RFID technology:

$$
\begin{aligned}
\pi_{D r}^{*}\left(\alpha Q_{D 0}^{*}, 0\right)= & p \alpha Q_{D 0}^{*}\left[1-F\left(\alpha Q_{D 0}^{*}, 0\right)\right] \\
& -r \alpha Q_{D 0}^{*} F\left(\alpha Q_{D 0}^{*}, 0\right) \\
& +s \alpha Q_{D 0}^{*}\left[1-F\left(\alpha Q_{D 0}^{*}, 0\right)\right]+v(1-\alpha) Q_{D 0}^{*} \\
& -w Q_{D 0}^{*}+(p+r) \int_{0}^{\alpha Q_{D 0}^{*}} x f(x, 0) d x \\
& -s \int_{\alpha Q_{D 0}^{*}}^{+\infty} x f(x, 0) d x
\end{aligned}
$$

$$
\begin{aligned}
= & p \alpha Q_{D 0}^{*}\left[1-F\left(\alpha Q_{D 0}^{*}, 0\right)\right] \\
& -r \alpha Q_{D 0}^{*} F\left(\alpha Q_{D 0}^{*}, 0\right) \\
& +s \alpha Q_{D 0}^{*}\left[1-F\left(\alpha Q_{D 0}^{*}, 0\right)\right]+v(1-\alpha) Q_{D 0}^{*} \\
& -w Q_{D 0}^{*}-(p+s+r) \sigma_{0} \phi\left(Z\left(S_{D 0}\right)\right) \\
& +\mu(p+s+r) \Phi\left(Z\left(S_{D 0}\right)\right)-\mu s \\
= & (p+s+r)\left[\mu \Phi\left(Z\left(S_{D 0}\right)\right)-\sigma_{0} \phi\left(Z\left(S_{D 0}\right)\right)\right] \\
& -\mu s .
\end{aligned}
$$

\section{Derivation of $(20)$}

By substituting the optimal order quantity into (16), we have the maximum expected profit of the retailer with adoption of RFID technology:

$$
\begin{aligned}
\pi_{D r}^{*}\left(Q_{D t}^{*}, t\right)= & p Q_{D t}^{*}\left[1-F\left(Q_{D t}^{*}, t\right)\right]-r Q_{D t}^{*} F\left(Q_{D t}^{*}, t\right) \\
& +s Q_{D t}^{*}\left[1-F\left(Q_{D t}^{*}, t\right)\right]-w Q_{D t}^{*} \\
& +(p+r) \int_{D t}^{Q_{D t}^{*}} x f(x, t) d x \\
& -s \int_{Q_{D t}^{*}}^{+\infty} x f(x, t) d x \\
= & p Q_{D t}^{*}\left[1-F\left(Q_{D t}^{*}, t\right)\right]-r Q_{D t}^{*} F\left(Q_{D t}^{*}, t\right) \\
& +s Q_{D t}^{*}\left[1-F\left(Q_{D t}^{*}, t\right)\right]-w Q_{D t}^{*} \\
& -(p+s+r) \sigma_{t} \phi\left(Z\left(S_{D t}\right)\right) \\
& +\mu(p+s+r) \Phi\left(Z\left(S_{D t}\right)\right)-\mu s \\
= & (p+s+r)\left[\mu \Phi\left(Z\left(S_{D t}\right)\right)-\sigma_{t} \phi\left(Z\left(S_{D t}\right)\right)\right] \\
& -\mu s .
\end{aligned}
$$

Proof of Theorem 11. By comparing the values of $S_{D 0}$ and $S_{D t}$, we can find that

$$
\begin{aligned}
S_{D t}-S_{D 0} & =\frac{p+s-w}{p+s+r}-\frac{\alpha(p+s-v)+v-w}{\alpha(p+s+r)} \\
& =\frac{(l / \alpha)(w-v)}{p+s+r} \geq 0 .
\end{aligned}
$$

According to (a), we can find that the service level will be improved with adoption of RFID technology by the decentralized supply chain; that is, $S_{D t} \geq S_{D 0}$. 
Proof of Proposition 12. If $\Delta_{D}$ stands for the profit variation of the decentralized supply chain with/without RFID technology, it can be derived that

$$
\begin{aligned}
\Delta_{D}= & \pi_{D}^{*}\left(Q_{D t}^{*}, t\right)-\pi_{D}^{*}\left(\alpha Q_{D 0}^{*}, 0\right) \\
= & \left\{(p+s+r)\left[\mu \Phi\left(Z\left(S_{D t}\right)\right)-\sigma_{t} \phi\left(Z\left(S_{D t}\right)\right)\right]\right. \\
& \left.-\mu s+(w-m-c)\left(\mu+Z\left(S_{D t}\right) \sigma_{t}\right)\right\} \\
& -\left\{(p+s+r)\left[\mu \Phi\left(Z\left(S_{D 0}\right)\right)-\sigma_{0} \phi\left(Z\left(S_{D 0}\right)\right)\right]\right. \\
= & \frac{\mu l}{\alpha}(m-v)+(p+s+r) \\
& \times\left[\sigma_{0} \phi\left(Z\left(S_{D 0}\right)\right)-\sigma_{t} \phi\left(Z\left(S_{D t}\right)\right)\right] \\
& +(w-m)\left(Z\left(S_{D t}\right) \sigma_{t}-\frac{Z\left(S_{D 0}\right) \sigma_{0}}{\alpha}\right) \\
& -c\left(\mu+Z\left(S_{D t}\right) \sigma_{t}\right) .
\end{aligned}
$$

Here we define a function $y_{D}=(\mu l / \alpha)(m-v)+(p+$ $s+r)\left[\sigma_{0} \phi\left(Z\left(S_{D 0}\right)\right)-\sigma_{t} \phi\left(Z\left(S_{D t}\right)\right)\right]+(w-m)\left(Z\left(S_{D t}\right) \sigma_{t}-\right.$ $\left.Z\left(S_{D 0}\right) \sigma_{0} / \alpha\right)$; we can discuss the service level in three cases as below.

When the service level is $0.5 \leq S_{D 0}<S_{D t}$, which means $0 \leq Z\left(S_{D 0}\right)<Z\left(S_{D t}\right)$, thus $\phi\left(S_{D 0}\right)>\phi\left(S_{D t}\right)>0$; also because $\sigma_{0}>\sigma_{t}>0, \sigma_{0} \phi\left(Z\left(S_{D 0}\right)\right) \geq \sigma_{t} \phi\left(Z\left(S_{D t}\right)\right)$.

(1) When $Z\left(S_{D t}\right) \sigma_{t}>Z\left(S_{D 0}\right) \sigma_{0} / \alpha$, then $y_{D}>0$ can be certain. In this case, the profit of supply chain will increase when the cost of adopting RFID technology $c \leq U_{\beta}^{\prime}$.

(2) When $Z\left(S_{D t}\right) \sigma_{t}=Z\left(S_{D 0}\right) \sigma_{0} / \alpha$, then $y_{D}>0$ can be certain. In this case, the profit of supply chain will increase when the cost of adopting RFID technology $c \leq U_{\beta}^{\prime}$.

(3) When $Z\left(S_{D t}\right) \sigma_{t}<Z\left(S_{D 0}\right) \sigma_{0} / \alpha$, if $w<$ $\beta /\left(Z\left(S_{D 0}\right) \sigma_{0} / \alpha-Z\left(S_{D t}\right) \sigma_{t}\right)+m$, then $y_{D}>0$ can be certain. In this case, the profit of supply chain will increase when the cost of adopting RFID technology $c \leq U_{\beta}^{\prime}$.

Proof of Proposition 13. In order to study the influence of adopting RFID technology on retailer's profit, we compare the retailer's maximum excepted profit with/without RFID technology. Suppose $\Delta_{D r}$ is retailer's profit variation; we get

$$
\begin{aligned}
\Delta_{D r}= & \pi_{D r}^{*}\left(Q_{D t}^{*}, t\right)-\pi_{D r}^{*}\left(\alpha Q_{D 0}^{*}, 0\right) \\
= & \left\{(p+s+r)\left[\mu \Phi\left(Z\left(S_{D t}\right)\right)-\sigma_{t} \phi\left(Z\left(S_{D t}\right)\right)\right]-\mu s\right\} \\
& -\left\{(p+s+r)\left[\mu \Phi\left(Z\left(S_{D 0}\right)\right)-\sigma_{0} \phi\left(Z\left(S_{D 0}\right)\right)\right]-\mu s\right\}
\end{aligned}
$$

$$
\begin{aligned}
= & \frac{\mu l}{\alpha}(w-v)+(p+s+r) \\
& \times\left[\sigma_{0} \phi\left(Z\left(S_{D 0}\right)\right)-\sigma_{t} \phi\left(Z\left(S_{D t}\right)\right)\right] .
\end{aligned}
$$

When the service level is $0.5 \leq S_{D 0}<S_{D t}$, which means $0 \leq Z\left(S_{D 0}\right)<Z\left(S_{D t}\right)$, thus $\phi\left(S_{D 0}\right)>\phi\left(S_{D t}\right)>0$; because $\sigma_{0}>\sigma_{t}>0, \sigma_{0} \phi\left(Z\left(S_{D 0}\right)\right) \geq \sigma_{t} \phi\left(Z\left(S_{D t}\right)\right)$. In this case, the retailer's profit will increase with decentralized supply chain adopting RFID technology.

Proof of Proposition 14. In order to study the influence of adopting RFID technology on supplier's profit, we compare the supplier's maximum excepted profit with/without RFID technology. Suppose $\Delta_{D s}$ is supplier's profit variation; we get

$$
\begin{aligned}
\Delta_{D s}= & \pi_{D s}^{*}\left(Q_{D t}^{*}, t\right)-\pi_{D s}^{*}\left(\alpha Q_{D 0}^{*}, 0\right) \\
= & {\left[(w-m-c)\left(\mu+Z\left(S_{D t}\right) \sigma_{t}\right)\right] } \\
& -\left[\frac{(w-m)}{\alpha}\left(\mu+Z\left(S_{D 0}\right) \sigma_{0}\right)\right] .
\end{aligned}
$$

Here we define a function $y_{D s}=(\mu l / \alpha)(m-w)+(w-$ $m)\left(Z\left(S_{D t}\right) \sigma_{t}-Z\left(S_{D 0}\right) \sigma_{0} / \alpha\right)$; we can discuss it as below.

When $0.5 \leq S_{D 0}<S_{D t}$, that means $0 \leq Z\left(S_{D 0}\right)<Z\left(S_{D t}\right)$. Because $\sigma_{0} \geq \sigma_{t}$, we cannot determine whether $Z\left(S_{D t}\right) \sigma_{t}$ or $Z\left(S_{D 0}\right) \sigma_{0} / \alpha$ is larger in this case.

(1) When $Z\left(S_{D t}\right) \sigma_{t} \geq Z\left(S_{D 0}\right) \sigma_{0} / \alpha$, there are two situations.

(i) $\alpha \in\left[V_{z}, 1\right]$ and $\alpha \in\left[V_{\mu}, 1\right]$ are essential to make the function $y_{D s} \geq 0$. Because $V_{\mu}>V_{z}$, we can find that $\alpha \in\left[V_{\mu}, 1\right]$ and the cost of RFID technology $c \in\left(0, U_{\alpha}^{\prime}\right)$; the supplier's profit will increase. Otherwise, it decreases: $\left(V_{z}=\right.$ $\left.Z\left(S_{D 0}\right) \sigma_{0} / Z\left(S_{D t}\right) \sigma_{t}\right)$.

(ii) $\alpha \in\left[V_{z}, V_{\mu}\right)$, then $Q_{D t}^{*}<Q_{D 0}^{*}$, so the function $y_{D s}<0$. In this case, adopting RFID technology will decrease the supplier's profit.

(2) When $Z\left(S_{D t}\right) \sigma_{t}<Z\left(S_{D 0}\right) \sigma_{0} / \alpha$, then $\alpha \in\left(0, V_{z}\right]$ and $Q_{D t}^{*}<Q_{D 0}^{*}$, so the function $y_{D s}<0$. In this case, the adoption of RFID technology will decrease the supplier's profit.

\section{Conflict of Interests}

The authors declare that there is no conflict of interests regarding the publication of this paper.

\section{Acknowledgments}

For helpful feedback and comments, the authors thank the following for their helpful discussions: Qi (Annabelle) Feng, George J Shanthikumar, Hui-xiao Yang, Yan-yi Xu, and Li Zhou. This work was supported by China Scholarship 
Council Foundation (201306740017), the National Natural Science Foundation of China (71171082), and the New Century Excellent Talents in University of China (NCET-110637). The authors also wish to acknowledge the helpful comments provided by anonymous referees.

\section{References}

[1] E. Fleisch and C. Tellkamp, "Inventory inaccuracy and supply chain performance: a simulation study of a retail supply chain," International Journal of Production Economics, vol. 95, no. 3, pp. 373-385, 2005.

[2] E. Sahin, J. Buzacott, and Y. Dallery, "Analysis of a newsvendor which has errors in inventory data records," European Journal of Operational Research, vol. 188, no. 2, pp. 370-389, 2008.

[3] Y. Rekik, E. Sahin, and Y. Dallery, "Analysis of the impact of the RFID technology on reducing product misplacement errors at retail stores," International Journal of Production Economics, vol. 112, no. 1, pp. 264-278, 2008.

[4] Y. Rekik, E. Sahin, Z. Jemai, and Y. Dallery, "Execution errors in retail supply chains: analysis of the case of misplaced products," International Journal of Systems Science, vol. 39, no. 7, pp. 727$740,2008$.

[5] E. Sahin and Y. Dallery, "Assessing the impact of inventory inaccuracies within a Newsvendor framework," European Journal of Operational Research, vol. 197, no. 3, pp. 1108-1118, 2009.

[6] Y. Rekik and E. Sahin, "Exploring inventory systems sensitive to shrinkage-analysis of a periodic review inventory under a service level constraint," International Journal of Production Research, vol. 50, no. 13, pp. 3529-3546, 2012.

[7] N. DeHoratius and A. Raman, "Inventory record inaccuracy: an empirical analysis," Management Science, vol. 54, no. 4, pp. 627641, 2008.

[8] M. A. Sieke, R. W. Seifert, and U. W. Thonemann, "Designing service level contracts for supply chain coordination," Production and Operations Management, vol. 21, no. 4, pp. 698-714, 2012.

[9] G. M. Gaukler, "Item-level RFID in a retail supply chain with stock-out-based substitution," IEEE Transactions on Industrial Informatics, vol. 7, no. 2, pp. 362-370, 2011.

[10] S. Whang, "Timing of RFID adoption in a supply chain," Management Science, vol. 56, no. 2, pp. 343-355, 2010.

[11] Z. Asif and M. Mandviwalla, "Integrating the supply chain with RFID: a technical and business analysis," Communications of the Association for Information Systems, vol. 15, no. 24, pp. 393-426, 2005.

[12] A. V. Iyer and M. E. Bergen, "Quick response in manufacturerretailer channels," Management Science, vol. 43, no. 4, pp. 559570, 1997.

[13] M. S. Chen and C. C. Chuang, "Extended newsboy problem with shortage-level constraints," International Journal of Production Economics, vol. 67, no. 3, pp. 269-277, 2000.

[14] D. Thiel, V. Hovelaque, and V. Thi Le Hoa, "Impact of inventory inaccuracy on service-level quality in $(\mathrm{Q}, \mathrm{R})$ continuous-review lost-sales inventory models," International Journal of Production Economics, vol. 123, no. 2, pp. 301-311, 2010.

[15] J. K. Jha and K. Shanker, "Single-vendor multi-buyer integrated production-inventory model with controllable lead time and service level constraints," Applied Mathematical Modelling. Simulation and Computation for Engineering and Environmental Systems, vol. 37, no. 4, pp. 1753-1767, 2013.
[16] P. Glasserman and Y. Wang, "Leadtime-inventory trade-offs in assemble-to-order systems," Operations Research, vol. 46, no. 6, pp. 858-871, 1998.

[17] J. Song and D. D. Yao, "Performance analysis and optimization of assemble-to-order systems with random lead times," Operations Research, vol. 50, no. 5, pp. 889-903, 2002.

[18] G. M. Gaukler, R. W. Seifert, and W. H. Hausman, "Item-level RFID in the retail supply chain," Production and Operations Management, vol. 16, no. 1, pp. 65-76, 2007.

[19] Y. Rekik, E. Sahin, and Y. Dallery, "A comprehensive analysis of the Newsvendor model with unreliable supply," OR Spectrum, vol. 29, no. 2, pp. 207-233, 2007.

[20] A. Z. Camdereli and J. M. Swaminathan, "Misplaced inventory and radio-frequency identification (RFID) technology: information and coordination," Production and Operations Management, vol. 19, no. 1, pp. 1-18, 2010.

[21] K. Sari, "Exploring the impacts of radio frequency identification (RFID) technology on supply chain performance," European Journal of Operational Research, vol. 207, no. 1, pp. 174-183, 2010.

[22] L. Zhang and J. Hu, "Effect of using RFID technology on supply chain profit and coordination based on VMI," Chinese Journal of Management, vol. 10, no. 4, pp. 590-596, 2013.

[23] T. Fan, L. Zhang, F. Wu, and H. X. Yang, "Effectof RFID technology on lead-time compression and coordination of supply chain's revenue," Chinese Journal of Management Science, vol. 21, no. 2, pp. 114-122, 2013.

[24] L. Zhang and T. Fan, "Research on the cost-sharing of adopting RFID technology among supply chain enterprise," Chinese Journal of Management Science, vol. 22, no. 4, pp. 25-35, 2014. 


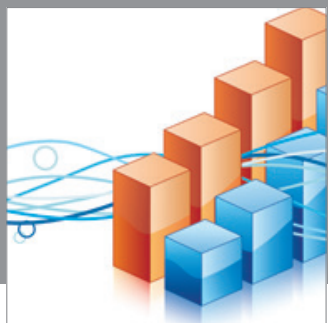

Advances in

Operations Research

mansans

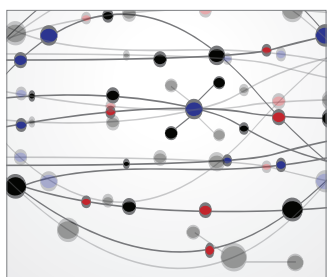

The Scientific World Journal
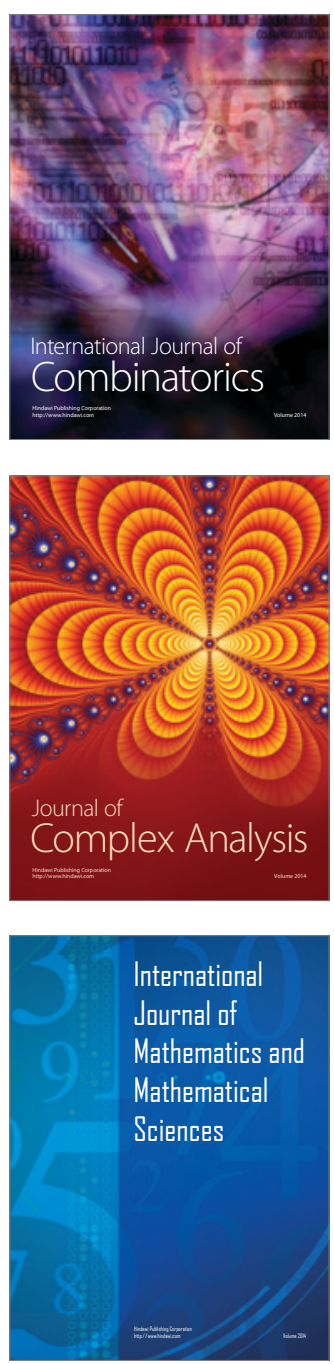
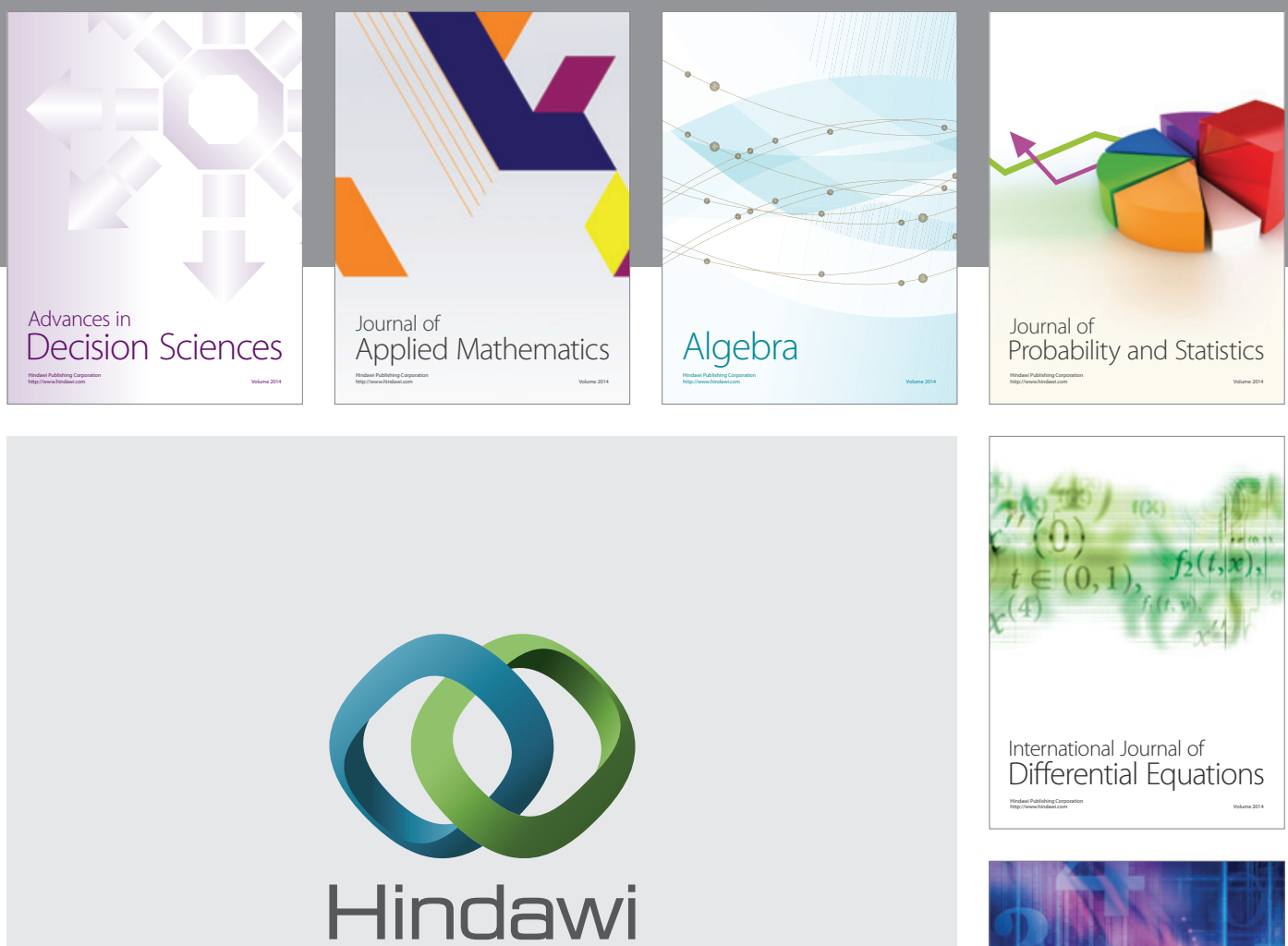

Submit your manuscripts at http://www.hindawi.com
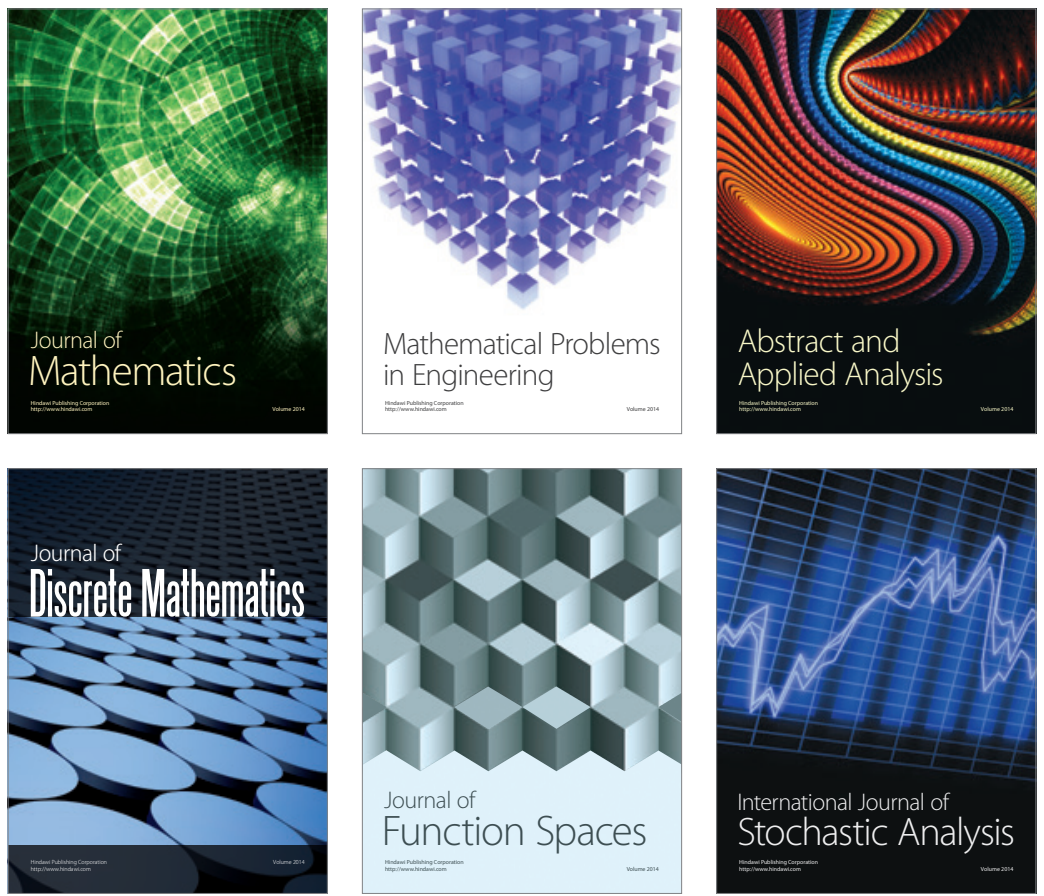

Journal of

Function Spaces

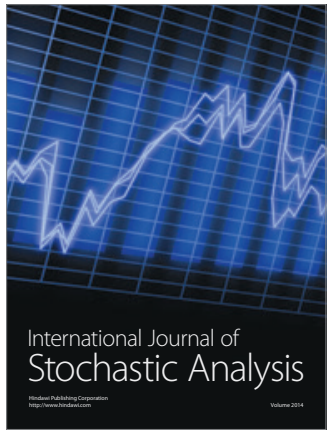

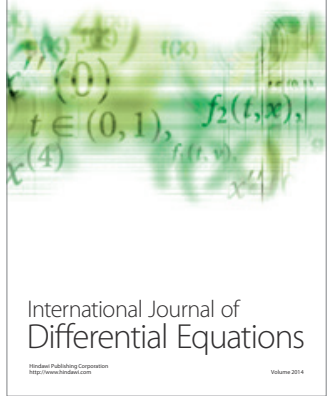
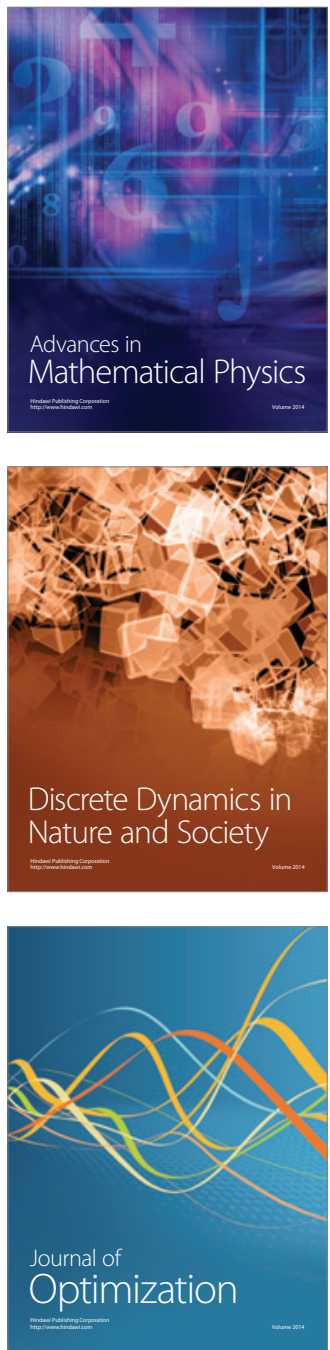